\title{
Review Article \\ Role of Orphan Nuclear Receptor DAX-1/NR0B1 in Development, Physiology, and Disease
}

\author{
Enzo Lalli ${ }^{1,2,3}$ \\ ${ }^{1}$ Institut de Pharmacologie Moléculaire et Cellulaire CNRS, 660 route des Lucioles, Sophia Antipolis, 06560 Valbonne, France \\ ${ }^{2}$ Associated International Laboratory (LIA) NEOGENEX CNRS, 06560 Valbonne, France \\ ${ }^{3}$ University of Nice Sophia Antipolis, 06560 Valbonne, France \\ Correspondence should be addressed to Enzo Lalli; ninino@ipmc.cnrs.fr
}

Received 8 December 2013; Accepted 25 March 2014; Published 20 May 2014

Academic Editor: Bo Zuo

Copyright (c) 2014 Enzo Lalli. This is an open access article distributed under the Creative Commons Attribution License, which permits unrestricted use, distribution, and reproduction in any medium, provided the original work is properly cited.

DAX-1/NR0B1 is an unusual orphan receptor that has a pivotal role in the development and function of steroidogenic tissues and of the reproductive axis. Recent studies have also indicated that this transcription factor has an important function in stem cell biology and in several types of cancer. Here I critically review the most important findings on the role of DAX-1 in development, physiology, and disease of endocrine tissues since the cloning of its gene twenty years ago.

\section{Introduction}

Nuclear hormone receptors are intracellular proteins that are responsible for sensing lipophilic substances and mediating their physiological actions, directly regulating the expression of target genes through binding to DNA. Nuclear receptors are implicated in a large variety of biological processes and have a special importance in development and endocrine functions (reviewed in [1]). A common feature of the members of this protein family is the presence of a conserved domain in the carboxyterminal part of the protein, which has the capacity to bind ligands (ligand-binding domain: LBD) modulating the transcriptional activity of the receptor and which folds as an antiparallel alpha-helical sandwich [2]. However, ligands are not known for all family members: the terminology of "orphan" is then used to indicate those proteins, which often possess a defined transcriptional function in the apparent absence of ligands. This spotlight paper is focused on a peculiar orphan receptor, DAX-1 (NR0B1 in the nuclear receptor official nomenclature), and will review the most important findings about its role in development, physiology, and disease.

\section{Cloning and Structure of DAX-1: An Unusual Orphan Receptor}

Cloning of the DAX-1 gene dates back to 1994. Previous studies by Bardoni and colleagues described a specific disorder of sex development, causing male-to-female phenotypic sex reversal (dosage-sensitive sex (DSS) reversal) in individuals bearing a normal $S R Y$ gene, associated with duplication of a minimal region spanning approximately $160 \mathrm{~kb}$ in chromosome Xp21 [3]. Cloning of expressed sequences in this region led to the identification of a two-exon gene encoding a novel member of the nuclear receptor family [4]. Remarkably, deletions, frameshift, missense, and stop mutations in this gene were found in patients affected with adrenal hypoplasia congenita (AHC), a congenital disorder characterized by impaired development of the adrenal cortex that can lead to adrenal insufficiency and is associated with hypogonadotropic hypogonadism (HHG) after puberty [4, 5]. Given its involvement in two different human diseases, either when present in double dosage or when mutated, the novel gene was named $D A X-1$, which stands for DSS, $A \mathrm{HC}$ critical region on chromosome $\underline{X}$, gene $\underline{1}$. The $\overline{D A X}-1$ gene 
product was classified among nuclear receptors because of the homology of its C-terminal domain with nuclear receptor LBDs. However, it stands apart in this class of proteins, since only the potential LBD is conserved in its protein structure compared with the other members of this class of molecules (Figure 1(a)). Noticeably, this domain harbors a ФФХЕФФ motif in its carboxyterminal portion, which is required for ligand-dependent transcriptional activation (AF-2) in other ligand-binding nuclear receptors and lies inside a structured alpha helix (helix H12) [2]. Another remarkable feature of the DAX-1 C-terminal domain is the presence of an unusually long insertion (26 amino acids) between the predicted helices $\mathrm{H} 6$ and H7. This insertion represents an outstanding feature of DAX-1, being absent in most other nuclear receptors. The conservation of this insertion in both human and mouse proteins suggests that it has a relevant role for DAX-1 function, but deletions in this region do not alter either DAX-1 subcellular localization or repressor function (see Section 4).

In sharp contrast to the C-terminal domain, the DAX-1 $\mathrm{N}$-terminal domain completely differs from classical nuclear receptors, which harbor here a zinc-finger DNA-binding domain. In DAX-1 a novel domain is present, harboring three repeats of a unique cysteine-rich motif about 70 amino acids long, with a last and incomplete repeat making the transition with the C-terminal domain of the protein. Inside each repeat a LXXLL motif is present, which is thought to have an important role in the mechanism of transcriptional regulation by DAX-1 (see Section 4). DAX-1 homologues have been cloned in a variety of species [6-12]. Remarkably, nonmammalian $D A X-1$ homologues have a much shorter $\mathrm{N}$-terminal domain, harboring only one repeat. The closest neighbor of $D A X-1$ in the nuclear receptor family is SHP (Short Heterodimer Partner; NR0B2), which harbors only one repeat in its short N-terminal domain [13]. $D A X-1$ and SHP homologues are present throughout vertebrates, indicating a paralogous origin through duplication from a common ancestral gene. Intriguingly, $D A X-1$ and $S H P$ both have important but distinct functions in metabolic and reproductive processes and share common mechanisms of gene regulation (reviewed in [14]).

\section{DAX-1 Expression Pattern during Embryogenesis and in the Adult}

$D A X-1$ has a restricted expression pattern during embryogenesis and in adult tissues. In the mouse embryo the adrenogonadal primordium is first detected at around day 9 of embryonic development (E9). Thereafter, adrenal and gonad lineages progressively become distinct while primordial germ cells colonize the still sexually undetermined bipotent embryonal gonad by E10. This differentiates into a testis or into an ovary after E11.5-E12. At around E11.5 cells derived from the neural crest infiltrate the adrenal primordium, giving origin to the adrenal medulla. The adrenal cortex and medulla become distinct by E16. Dax-1 expression is detected in the adrenogonadal primordium in both sexes starting at E10.5-11 and continues to be expressed in the adrenal thereafter until adult life, being restricted to the cortical region $[6,15]$.

In the developing male gonad, at E12.5, Dax-1 is expressed both in the testicular cords, which contain primordial germ cells and the Sertoli cells, and in the interstitial region of the testis, which harbors the steroidogenic Leydig cells. Dax1 expression becomes then progressively localized mostly to the interstitial region, suggesting that the fetal Leydig cells are the predominant site of expression at later stages in development. In the female, Dax-1 expression is present throughout the ovarian primordium starting from E12.5. Remarkably, cell clusters located at the junction between the embryonal gonad and the adjacent mesenchymal tissue express Dax-1 at high levels in both sexes $[6,15]$.

Discordant results have been published concerning the relative intensity of Dax-1 expression in the developing male compared to the female gonad. In the mouse, Swain et al. reported a sexual dimorphism in Dax-1 mRNA expression after E12, with expression levels decreasing in the testis and remaining elevated in the ovary [6]. Conversely, Ikeda et al. did not detect a dimorphic pattern of Dax-1 expression in the late stages of gonadal development, with its transcript levels being downregulated after E14.5 in both testis and ovary [15]. In contrast, in another study Dax-1 mRNA levels were reported to be high in the developing rat testis and low in the ovary at E18.5 [16]. In a further study analyzing Dax1 protein expression, Ikeda et al. reported a more complex pattern of Dax-1 expression in the developing mouse gonads, with levels gradually decreasing in the testis until E16.5 and then increasing again at E18.5, while Dax-1 expression in the ovary continues to be high until E14.5 but significantly decreased at E16.5 and E18.5 [17]. These discrepancies may be due to the different methods (in situ hybridization using radioactive and nonradioactive probes, RNAse protection, immunoblotting, and immunohistochemistry) used for Dax1 mRNA or protein detection and to the different animal species under study. Furthermore, it is possible that an intellectual bias towards a certain hypothesis about the role of Dax-1 in sex determination may have influenced the interpretation of experiments looking at Dax-1 expression in the developing gonad (see Section 7).

A remarkable sexually dimorphic expression of Dax-1 exists in the adult mouse adrenal cortex, being restricted to the outer region in the male and extended to the entire cortex in the female. It has been shown that this dimorphic expression is under the control of sex hormones, being abolished by gonadectomy and restored by testosterone replacement in gonadectomized males [18]. Consistent with these data, androgen receptor is able to repress Dax-1 promoter activity in a ligand-dependent fashion. In the adult gonads, Dax-1 is expressed in Leydig and Sertoli cells in the testis and in granulosa and theca cells in the ovary [15]. Interestingly, in Sertoli cells Dax-1 expression is regulated during spermatogenesis and peaks during the androgen-sensitive phase of the spermatogenic cycle [19]. Germ cells do not express Dax-1.

In other tissues Dax-1 has a restricted pattern of expression both in the embryo and in the adult. At E9.5 intense Dax-1 expression can be detected in Rathke's pouch (the embryonic structure derived from midline oral ectoderm that 


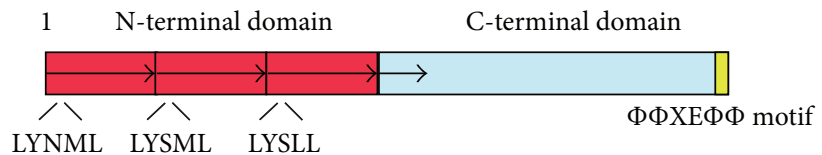

(a)

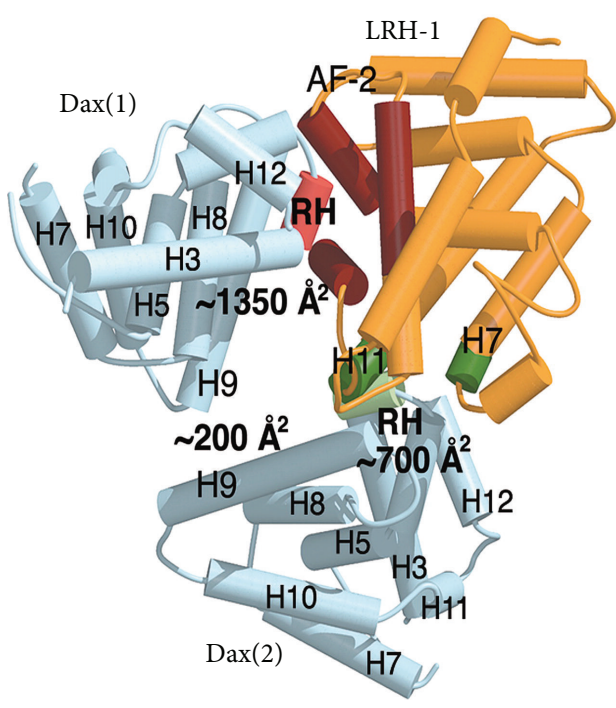

(b)

FIGURE 1: Structure of the DAX-1 protein. (a) Schema of the human DAX-1 protein. The N-terminal repeats are indicated with arrows, together with the last incomplete repeat that extends into the C-terminal domain. The position and sequence of the LXXLL motifs in the N-terminal domain as well as the conserved motif in the C-terminal domain are shown. (b) The three-dimensional structure of the Dax-1:LRH-1 complex. LRH-1 is shown in yellow; the two Dax-1 molecules are shown in blue. The structural elements involved in the binding of the first Dax-1 to LRH-1 are shown in rose (RH site) and dark red (AF-2 region). The structural elements at the second Dax-1:LRH-1 interface are indicated in light and dark green. From [61]. Copyright 2008 National Academy of Sciences, USA.

lies in direct contact with the floor of the diencephalon and from which the anterior pituitary originates), which later (E11.5) becomes restricted to its dorsal part and decreases markedly at later times in development (E13.5) [17]. At E14.5 Dax-1 expression is first detectable in scattered cells present in the anterior part of Rathke's pouch. In the postnatal pituitary gland, Dax-1 expression is restricted to gonadotropes [15]. Dax-1 is also expressed in the diencephalon at E9.5-E11.5 and postnatally is detectable in the ventromedial hypothalamic nucleus (VMH) and possibly other brain regions (arcuate nucleus, amygdala, hippocampus, and cerebral cortex) [17].

During human embryo development, the adrenal primordium takes origin from intermediate mesoderm, forming a distinct structure by 33-day postconception (dpc), and then rapidly grows in size during the embryonic period. By $52 \mathrm{dpc}$ an inner group of large eosinophilic cells (the fetal zone) occupies the inner part of the human embryonic adrenal cortex, which express the steroidogenic enzyme CYP17 at high levels. Small, densely packed, nonsteroidogenic cells surround the fetal zone and form the definitive zone, from which the adult adrenal cortex will form after birth and involution of the fetal zone [20]. At later gestational times (18 weeks) a transitional zone becomes evident, being situated between definitive and fetal zones and harboring cells of intermediate characteristics. DAX-1 can be detected in the human fetal adrenal gland starting from its inception at $33 \mathrm{dpc}$ and is expressed at high levels both in fetal and definitive zones at $52 \mathrm{dpc}$, while its expression decreases thereafter [21]. In humans, the sexually indifferent gonadal ridge, containing both somatic and primordial germ cells, can also be identified around $33 \mathrm{dpc}$. At this stage of development, the gonadal ridge already expresses $D A X-1$ at levels lower than in the adjacent adrenal primordium. DAX-1 expression persists during the whole period when the gonad is undifferentiated and continues at low levels in both sexes after testis and ovarian determination [22].

In most sites of Dax-1 expression a remarkable, even if not complete, overlap exists with the expression of another nuclear receptor, steroidogenic factor-1 (SF-1/Ad4BP; NR5A1 in the nuclear receptor nomenclature), which has a pivotal role in the development of adrenal glands and gonads [23, $24]$ and has a similar tissue-restricted pattern of expression $[15,25]$. Functional interactions between DAX-1 and SF-1 are described in Section 4.

\section{Mechanisms of Transcriptional and Posttranscriptional Regulation of Gene Expression by DAX-1}

The characterization of DAX-1 as a member of the nuclear receptor family prompted studies of its transcriptional regulatory properties. Data published already in its cloning paper showed that DAX-1 is able to repress ligand-induced transcriptional activation by the retinoic acid receptor alpharetinoid X receptor alpha heterodimer [4]. Further studies, mostly focused on other members of the nuclear receptor family, confirmed and extended those early results, showing that DAX-1 generally works as a repressor of gene expression activated by other transcription factors. 
The overlapping expression patterns of DAX-1 and SF1 provided a rationale for a blooming of studies investigating the functional interplay between their transcriptional functions. SF-1 binds to and activates transcription from multiple P450 steroidogenic enzyme promoters and other genes involved in steroidogenesis, metabolism, and reproductive function (reviewed in [24]). Furthermore, gene knockout studies demonstrated that SF-1 has an essential role in the development of adrenal glands and gonads [23]. SF1 transcriptional activity can be regulated by phospholipid ligands which bind inside the hydrophobic pocket present in its LBD [26-28]. Seminal studies demonstrated that DAX-1 is able to downregulate transcriptional activation driven by SF1 on steroidogenic genes through a powerful transcriptional repression domain situated in the protein C-terminal, LBDlike domain. DAX-1 mutants found in AHC patients have invariably lost their transcriptional repression properties (see Section 6) [29-32]. Further studies have shown that Dax-1 expression correlates negatively with the expression of steroidogenic genes in a cell line derived from targeted tumorigenesis of the mouse adrenal cortex [33] and that it also works as a repressor of steroidogenesis in vivo [34]. The framework has then been established with DAX-1 acting as a global negative regulator of genes involved in steroid hormone production and metabolism in steroidogenic tissues (reviewed in [35]). The E3 ubiquitin ligase RNF31 interacts with DAX-1 and cooperates with it in transcriptional repression of steroidogenesis, probably by stabilizing the protein through monoubiquitination [36]. Interestingly, $D A X-$ 1 expression is in turn positively regulated by SF-1 [37-40], suggesting that DAX-1 is part of a regulatory loop that has the function of limiting SF-1 activity (see Section 5). Since the level of SF-1 transcriptional activity is a crucial parameter for the selection and regulation of its downstream target genes [41-43], the action of DAX-1 as a SF-1 repressor has probably a great relevance in the process of adrenal gland development. At early stages in development, the expression pattern of Dax1 overlaps with that of $S f-1$, whose expression is driven at this time by the fetal adrenal enhancer (FAdE) [44], while, at later times (E17.5), Dax-1 is found localized in the outer part of the adrenal primordium (from which the adult adrenal cortex will originate). At this stage FAdE expression is restricted to the inner part of the adrenal cortex (identified as the Xzone postnatally). This pattern of expression indicates that Dax-1 may suppress FAdE expression during the transition from the fetal to the adult adrenal differentiation program [44] and suggests that a fine balance between Sf-1 and Dax1 is needed for normal adrenocortical development. These data also provide clues to explain how loss of function of two transcription factors as SF-1 and DAX-1, one working as an activator and the other one as a repressor of transcription, respectively, leads to the same adrenal hypoplasia phenotype (see also below Section 7).

A mechanism employed by DAX-1 to exert its negative transcriptional effect involves direct protein-protein interaction with the C-terminal domain of SF-1 [16, 29, 45] and other nuclear receptors [46-57] (see the following list of transcription factors reported to interact with DAX1: SF-1 [29, 45]; LRH-1 [45]; $\operatorname{ER} \alpha / \operatorname{ER} \beta[46] ; \operatorname{AR}[47,48]$;
PR [48]; GR [51]; Nur77 [49]; ERR $\gamma$ [50]; PPAR $\gamma$ [52]; HNF4 $\alpha$ [53]; LXR $\alpha$ [54]; FXR [55]; CAR [56]; Esrrb [57]; Oct3/4 [58]; EWS/FLI1 [59]). In many cases protein-protein interactions between DAX-1 and other nuclear receptors were suggested to be mediated via the LXXLL motifs present in the DAX-1 N-terminal domain, which would occupy the coactivator-binding surface in the nuclear receptor LBD, competing with positive transcriptional cofactors and also recruiting the strong transcriptional silencing domain present in the DAX-1 C-terminus to the complex [46]. However, while several studies were able to show interaction of DAX-1 with SF-1 and other nuclear receptors in the yeast and mammalian two-hybrid systems, published data showing that those factors interact on DNA forming a distinct ternary complex are scanty. This suggests that additional factors are required for interaction between DAX-1 and nuclear receptors, one of them probably being local DNA conformation itself. It has in fact been shown that DAX-1 is able to bind to hairpin DNA structures, which are required for transcriptional repression of SF-1-dependent activity of some promoters $[31,60]$. Another piece of evidence complicating the picture stems from the only structural study published to date describing the crystal structure of the C-terminal domain of mouse Dax-1 in a complex with the LRH-1 LBD. Sablin et al. showed that only the Dax-1 C-terminal domain, and not the N-terminal domain, is able to interact with the LRH-1 LBD in vitro, forming a heterotrimer with a Dax1 :LRH-1 ratio of $2: 1$ [61]. The structure of the complex shows that a novel conserved sequence motif (PCFXXLP; the "repressor helix") in the Dax-1 C-terminal domain mediates interaction with the coactivator groove of the LRH-1 LBD and with an additional surface comprising parts of helices H7 and H11 (Figure 1(b)). Mutagenesis of repressor helix residues drastically impairs repression of LRH-1-induced transactivation by Dax-1. It remains to be determined whether interaction of DAX-1 with other nuclear receptors involves the same molecular surfaces described in the case of LRH1. Noticeably, the structure of the mouse Dax-1 C-terminal domain shows insufficient space to harbor even small ligands. This suggests that Dax-1 is a true orphan receptor. However, because of the limited similarity between the human and the mouse DAX-1 proteins (76.3\%), the possibility still exists that ligands may modulate the transcriptional activity of human DAX-1.

DAX-1 was described as being able to form homodimers and also heterodimers together with SHP/NR0B2 [62]. The DAX-1 amino and carboxyl termini have been reported to interact in an antiparallel fashion to form homodimers, with involvement of the LXXLL and AF-2 motifs. The same domains are involved in heterodimeric interaction of DAX-1 with SHP. It has been suggested that DAX-1 homodimers may function as reservoirs of the protein, which may dissociate in a fashion regulated by signalling pathways to become available to interaction with other partners. This scenario, however, remains speculative.

Activity of the DAX-1 transcriptional silencing domain requires corepressors [30], transcriptional cofactors mediating binding to histone deacetylases and other protein complexes producing specific histone modifications that lock 
chromatin in an inactive state, thus inhibiting PollI transcription. Among corepressors, DAX-1 was shown to interact with $\mathrm{N}-\mathrm{CoR}$ [63] and Alien [64], even if further studies have ruled out a role of N-CoR as a bona fide DAX-1 corepressor [65]. However, site-directed mutagenesis of conserved surface residues in DAX-1, which in other nuclear receptors are involved in corepressor interaction, does not impair DAX1 transcriptional silencing properties (see Section 6) [66]. These data suggest that cofactors different from known nuclear receptor corepressors mediate DAX-1 transcriptional silencing activity.

It is well known that transcription factors acting as constitutive or regulated repressors of gene expression play a fundamental role in developmental processes in a variety of species [67]. An example within the nuclear receptor family is provided by the chicken ovalbumin upstream promoter transcription factors I and II (COUP-TFI and COUPTFII) orphans, which are required for development of the nervous and cardiovascular system, respectively [68, 69]. A mechanism that has been suggested to explain DAX-1 function in adrenal development consists in the repression of the expression of differentiation genes (StAR, steroid hydroxylases) in the developing adrenal cortex, which may be required to allow proliferation of definitive zone cells in the critical postnatal period in the human adrenal cortex. In the absence of a functional DAX-1, abnormally early expression of steroidogenic genes may be activated in definitive zone cells of the adrenal cortex, which could impair their proliferation and further differentiation. Adrenal hypoplasia would then develop in those individuals after the physiological postnatal regression of the fetal zone [35] (see Section 6).

Another peculiar property of DAX-1 is its ability to also bind RNA [70]. By immunofluorescence and electron microscopy, DAX-1 was visualized both in the nucleus and in the cytoplasm in steroidogenic cell lines (human adrenocortical H295R and the mouse Leydig MA-10 cells). In the nucleus, DAX-1 is preferentially associated with ribonucleoprotein (RNP) fibrils in the perichromatin region and with fibrillar constituents in chromatin-rich regions. In the cytoplasm, DAX-1 was frequently found associated with ribosome-rich areas. Biochemical fractionation confirmed that a portion of the cytoplasmic DAX-1 protein pool is found associated with polyribosomes, which are actively involved in protein translation, as part of large mRNP complexes containing poly $(\mathrm{A})^{+}$RNA. DAX-1 is able to directly bind RNA homopolymers in vitro, with different binding specificity. The nucleocytoplasmic shuttling activity of DAX1 suggests that it is implicated in mRNA export from the nucleus to polyribosomes and possibly in the control of their translation. Both DAX-1 N- and C-terminal domains are able to directly bind RNA homopolymers in vitro, but the full-length protein has a RNA-binding specificity which differs from each domain taken singularly. Remarkably, DAX-1 AHC missense mutants have a reduced RNA-binding activity compared to the wild-type protein. This suggests that the RNA-binding properties of DAX-1 are relevant to its physiological function during adrenal development and that posttranscriptional regulation of gene expression by DAX1 may play an important role. It can also be speculated that the RNA-binding activity of DAX-1 may be related to its transcriptional repressor properties, possibly mediating interaction with RNA species that are part of transcriptional coregulator complexes. One nuclear receptor cofactor known to work as a RNA molecule is the steroid receptor activator (SRA). A report has indeed suggested that mouse Dax1 recruits SRA to SF-1, with the result of increasing its transactivation of some of its target promoters $(M c 2 R$, StAR) [71]. However, several inconsistencies in the data obtained by $\mathrm{Xu}$ et al. are present. First, we could never observe activation of $M c 2 R$ and $S t A R$ promoter activity by DAX-1 cotransfection, which in our hands was invariably associated with promoter repression $[31,72]$. Second, Xu et al. show only a very modest effect of cotransfected Dax-1/SRA in increasing activation of a $M c 2 R$-luc construct by SF-1. Paradoxically, this effect was also present when the isolated Dax-1 C-terminal domain was coexpressed, which, according to those authors, has very reduced SRA binding activity compared to the fulllength protein [71]. Third, the Dax-1 mutant $\Delta \mathrm{V} 271$, which corresponds to the human AHC mutant $\Delta \mathrm{V} 269$, behaves similarly to the wild type. However, the localization of this mutant is shifted to the cytoplasm (see below Section 6) $[65,66]$ and it is difficult to explain how it may regulate promoter expression in the nucleus. Further studies are then needed to assess the role of potential interactions between DAX-1 and RNA transcriptional cofactors in the regulation of gene expression. In a restricted number of other studies DAX-1 has also been reported to function as a transcriptional activator. It remains possible that transcriptional activation by DAX-1 may be promoter-specific, as shown for the $P B X 1$ promoter by Ferraz-de-Souza and collaborators [73]. However, a detailed molecular characterization of the DAX1 transcriptional effect, for instance, by the investigation of the activity of the AF-2 DAX-1 mutant, was lacking in that study. Moreover, in another study transcriptional activation by DAX-1 was detected on SF-1 activated CYP11B1 promoter in adrenocortical H295R cells [74]. However, those cells express endogenous DAX-1, which may influence the results obtained. Remarkably, in the same study DAX-1 worked as a transcriptional repressor when transfected in other cell types. Additionally, in a recent study, mouse Dax-1 was reported to upregulate Oct4 promoter expression in mouse embryonic stem (ES) and embryonic carcinoma F9 cells by interacting with LRH-1 and SRA [75]. However, also in this case both cell types express endogenous Dax-1, with possible confounding effects on the results of transient transfection assays. I have also previously commented on the reported interaction between Dax-1 and SRA. Considering all those results, it is clear that further studies are needed to convincingly demonstrate a potential direct positive transcriptional effect of DAX-1 on gene promoter activity.

\section{Regulation of DAX-1 Expression}

A transcription factor that has an important function in early adrenogonadal development and that was reported to regulate Dax-1 expression is WT1, through binding to 
promoter-proximal sites [76]. However, the relevance of Dax1 regulation by WT1 in vivo during development is unknown. Conversely, several lines of evidence implicate the nuclear receptor SF-1 in the regulation of $D A X-1$ expression. Initial studies indicated that a conserved SF-1 binding site situated close to the transcription start site in the $D A X-1$ promoter is important for basal and SF-1-stimulated promoter activity in adrenocortical H295 cells [37, 38]. However, deletion of the sequence harboring the homologous binding site has little effect on basal and SF-1-stimulated activity of the mouse Dax1 promoter in Leydig MA-10, adrenocortical Y1, and pituitary gonadotrope $\alpha$ T3 cells. Moreover, Dax-1 expression is still present in the genital ridge and the hypothalamus of $S f-1$ null mice [15]. These results led Ikeda and coauthors to suggest that SF-1 does not play an essential role in the regulation of Dax-1 expression. However, further studies showed that Dax1 expression is significantly reduced in tissues from $S f-1$ null mice [39] and that a $500 \mathrm{bp}$ conserved region $4 \mathrm{~kb}$ upstream of the Dax-1 coding sequence directs reporter gene expression in the developing gonad [40]. This region harbors a SF-1 binding site, which is essential for activity, while SF-1 sites that are proximal to the transcription start site of the gene are important to regulate Dax-1 expression levels. Remarkably, a $60 \mathrm{Mb}$ chromosomal inversion on the $\mathrm{X}$ chromosome was identified in an AHC kindred with one of the inversion breakpoints situated in the conserved region, which causes relocation of the SF-1 binding site implicated in mouse studies [77]. Conversely, a submicroscopic $250 \mathrm{~kb}$ deletion upstream of $D A X-1$, which left intact the distal SF-1 binding site, was associated with male-to-female sex reversal with no adrenal insufficiency [78]. Taken together, these data suggest that distal regulatory elements have an important function in the regulation of $D A X-1$ expression.

Another important actor in the control of $D A X-1$ expression is represented by the $\mathrm{Wnt} / \beta$-catenin pathway. This pathway has a pivotal role in the regulation of proliferation and differentiation of progenitor cells in the adrenal cortex and gonads and is also implicated in tumorigenesis. Soluble factors belonging to the Wnt family interact with Frizzled and LRP membrane receptors and inhibit $\beta$-catenin degradation, allowing its stabilization and nuclear translocation to interact with LEF/TCF and other transcription factors (reviewed in [79]). Starting from the common phenotype of DSS with disorders of sexual development (DSD) associated with duplications in 1p31-35, which harbors the WNT4 gene (studies in mice have revealed to be involved in female sexual development [80]), it was shown that transfection of Wnt4 resulted in upregulation of Dax-1 expression in mouse Sertoli and Leydig cell lines [81]. Further studies showed that Dax1 expression is downregulated in the developing gonad of Wnt4 null mice and that Dax-1 expression is stimulated by $\beta$-catenin, which acts synergically with SF-1 to activate Dax1 promoter expression [82]. Importantly, $\beta$-catenin activation also controls Dax-1 expression in mouse embryonic stem (ES) cells (see Section 8).

In contrast with the positive action of the Wnt/ $\beta$-catenin pathway, the cAMP pathway has a negative effect on Dax1 expression in several contexts. In the rat primary Sertoli cells, Dax-1 expression is regulated negatively by FSH [19].
This action is mimicked by a cell-permeant form of its second messenger cAMP, while phorbol esters and testosterone have no effect. The effect of cAMP on Dax-1 expression in the Sertoli cells requires transcription and de novo protein synthesis. Similar effects of cAMP pathway activation to negatively modulate Dax-1 expression have been reported in bovine glomerulosa cells stimulated with the adenylate cyclase activator forskolin [83], in rat ovarian granulosa cells after FSH stimulation [84], in mouse Leydig K28 cells after LH stimulation [49], and in mouse adrenocortical ATC-1 cells after ACTH stimulation [33]. In the other mouse adrenocortical cell line Y1, ACTH can antagonize the glucocorticoiddependent synergy between SF-1 and glucocorticoid receptor in the activation of the Dax-1 promoter [85]. The effect of the cAMP pathway, which invariably stimulates steroid hormone production, on Dax-1 expression in several systems can be considered as a mechanism to decrease the levels of an endogenous repressor to allow for efficient steroidogenesis.

\section{AHC: Clinical Features and Pathogenesis}

AHC is a hereditary disease of the adrenal cortex, which in the majority of cases manifests as a syndrome of adrenal insufficiency early in life [86]. Clinical features include failure to thrive, vomiting, hyperpigmentation, and shock, with biochemical tests showing hyponatremia/hyperkalemia, low cortisol and aldosterone levels, and elevated ACTH and plasma renin activity. However, a large clinical spectrum exists (sometimes even within the same family), with some cases being diagnosed later in childhood or in adulthood, others presenting isolated mineralocorticoid deficiency with apparently preserved glucocorticoid production [74], or even some cases being clinically silent. Two forms of the disease have been identified based on pathological and inheritance criteria as follows.

(i) An X-linked form, characterized by the absence of the permanent zone of the adrenal cortex and by the presence of large vacuolated cells, similar to fetal adrenal cells is presented. This form of AHC can be found associated with glycerol kinase deficiency and the Duchenne muscular dystrophy as a contiguous gene syndrome caused by deletion of multiple genes on chromosome Xp21.

(ii) A rare autosomal recessive or sporadic form with small (miniature-type) cells is presented.

AHC can be a lethal condition if untreated because of salt and water loss due to deficit of mineralocorticoid hormones produced by the adrenal and reduced resistance to stress.

$D A X-1$ mutations are responsible for the X-linked form of AHC [4,5]. A distinctive feature of this form is its association with HHG, which becomes clinically evident after puberty and is caused by a combined hypothalamic failure in $\mathrm{GnRH}$ release and pituitary defect in LH/FSH production [87]. Remarkably, it has been reported that in patients with $\mathrm{AHC}$-associated $\mathrm{HHG}$ the physiological 
postnatal transient activation of the hypothalamic-pituitarygonadal axis (minipuberty of infancy) is normal or even prolonged in time, while the onset of gonadotropin production at puberty is impaired [88-90]. In rare cases HHG may be the presenting or the only symptom of the disease [91-93]. Furthermore, GnRH or gonadotropin treatments are usually inefficient to improve spermatogenesis in patients carrying $D A X-1$ mutations, suggesting that a primary testicular defect is present. This hypothesis is reinforced by studies in Dax-1 null mice (see Section 7). A case has been recently reported of successful in vitro fertilization by intracytoplasmic injection of spermatozoa obtained from the testicular tissue of an azoospermic patient carrying a DAX-1 mutation [94]. Strikingly, in contrast with the prevalent HHG phenotype, in rare cases $D A X-1$ mutations or deletions can even cause precocious puberty, which may be of central origin $[95,96]$ or possibly due to chronic ACTH stimulation of the testicular Leydig cells [97]. In exceptional cases, AHC/HHG due to $D A X-1$ deletion or mutation has also been diagnosed in women [91, 98]. Gene conversion or skewed inactivation of the normal $\mathrm{X}$ chromosome may account for this unusual phenotype.

It has been estimated that approximately one-third of the boys with $\mathrm{X}$-linked AHC bear a deletion in DAX1 , with a contiguous gene syndrome occurring in about half of these cases. Conversely, nearly two-thirds of those patients have a mutation inside the $D A X-1$ coding sequence (point mutations, dinucleotide mutations, small duplications and deletions, and indel mutations), which can produce insertions/deletions inducing in most cases a frameshift of the coding sequence or amino acid changes (nonsense and missense) [4, 5, 99-101]. Notably, little correlation exists between the type of $D A X-1$ mutations or their position in the genomic sequence and age at presentation or severity of the disease.

Of particular interest are $D A X-1$ missense mutations, which represent around $20 \%$ of all mutations and which have been very valuable to elucidate the function of the protein. In the overwhelming majority of cases they are localized in the DAX-1 C-terminal domain [4, 5, 99-101]. Only in two cases, $D A X-1$ missense mutations have been found localized in the N-terminal domain of the protein: one mutation $(\mathrm{C} 200 \mathrm{~W})$ affects a nonconserved residue and is associated with childhood-onset AHC [102], while the other mutation at the level of a highly conserved residue (W105C) was associated in one proband with apparently isolated mineralocorticoid deficiency but was also present in three asymptomatic male siblings [74].

The common feature of all DAX-1 missense mutants is their impaired transcriptional regulatory activity compared to the wild-type protein $[29,30]$. In general, little correlation exists between the age of onset of the disease and the magnitude of the transcriptional defect of the mutant DAX-1 protein. A DAX-1 mutation (I439S) found in a patient with adrenal insufficiency diagnosed at adult age and incomplete HHG has only weakly reduced transcriptional repression activity [103]. A patient has also been described with lateonset adrenal insufficiency and gonadal failure bearing an amino terminal nonsense mutation in $D A X-1$. An alternate downstream translation initiation site in the $D A X-1$ mRNA allowed production of a truncated form of the protein that retains partial transcriptional activity [104]. However, partial defects in transcriptional activity also characterize other DAX-1 mutants found in patients with childhood-onset AHC [105]. These data suggest that modifier genes and possibly also epigenetic factors may influence the clinical manifestations in patients bearing DAX-1 mutations.

A significant breakthrough to identify the mechanism explaining the impaired transcriptional activity by DAX1 missense mutants came from the discovery that they all have a defect in nuclear localization, which is of variable severity according to the position of the residue affected by the mutation $[65,66]$. An inverse relationship exists between the repression activity of the mutant DAX-1 and the degree of its cytoplasmic localization (Figure 2). Limited proteolysis experiments showed that DAX-1 AHC missense mutations alter the structure of the protein C-terminal domain probably determining its misfolding and allowing the interaction of the protein with anchoring sites that retain it in the cytoplasm, since the protein nuclear localization signal (NLS) lies in the DAX-1 N-terminal domain and is not affected by the mutations $[65,66]$. Remarkably, the misfolded DAX-1 Cterminal domain can also induce cytoplasmic retention of a fused heterologous DNA-binding domain (yeast Gal4) possessing its own NLS. On the other hand, the misfolded DAX-1 AHC mutants do not shift localization of SF-1 to the cytoplasm. The misfolding of the mutated DAX-1 proteins can also account for their diminished RNA-binding activity (see Section 4).

It is interesting to remark that the magnitude of the defects of nuclear localization and transcriptional repression activity by DAX-1 missense mutants varies according to the chemical nature of the mutated residue. Val 269 (targeted by the in-frame deletion $\triangle \mathrm{V} 269$ in an AHC patient) is a conserved residue in the DAX-1 C-terminal domain lying in the $\mathrm{H} 3$ helix, having a critical role in the stabilization of the structure of the nuclear receptor LBD fold. Experiments replacing V269 with other amino acids at the same position showed that the mutants harboring the hydrophobic residues alanine, isoleucine, and leucine retained wild-type nuclear localization and transcriptional repression, while the V269R mutation shifted protein localization to the cytoplasm with consequent loss of its transcriptional activity, mimicking the effect of the V269 deletion. Also, Ile 439 (targeted by the I439S AHC mutation) is predicted to be localized at the C-terminal portion of the H10 helix in the DAX-1 C-terminal domain structure. In this position a hydrophobic residue is conserved in all nuclear receptors, making contacts with residues in helix H7. The substituted serine has a weakly hydrophobic character, which is predicted to only partially perturb the hydrophobic environment in which the residue is situated. Consistent with this interpretation, loss of transcriptional activity and impaired nuclear localization are inversely proportional to the hydrophobic character (leucine $>$ alanine $>$ serine) of the residue present in this position [66]. On the other hand, transcriptional repression by DAX-1 is insensitive to mutagenesis of a putative corepressor binding surface. A partially overlapping molecular surface is used by nuclear 


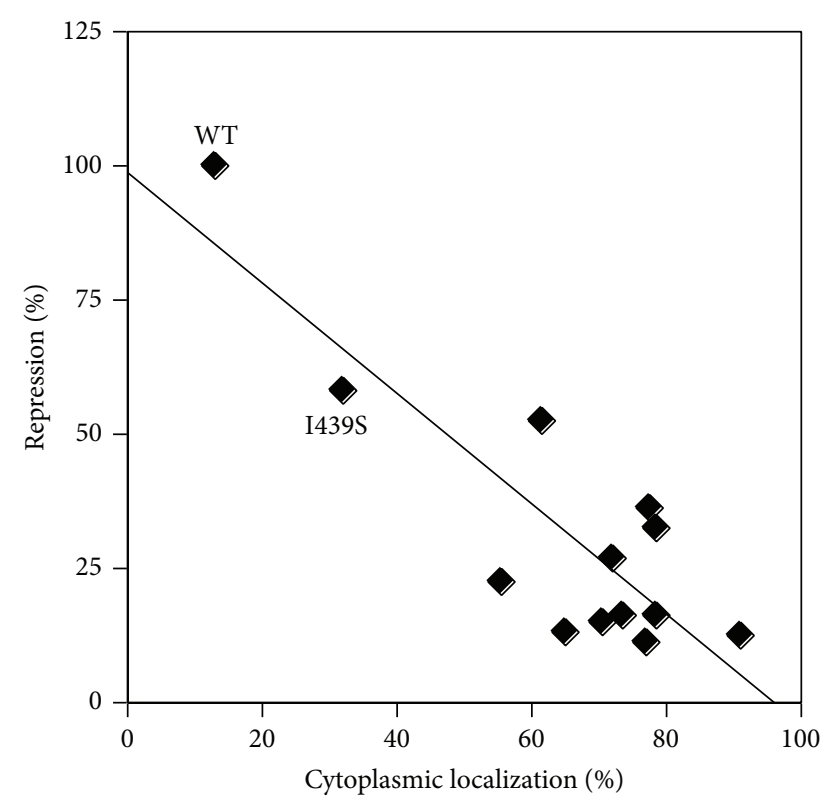

FIgURE 2: Correlation between loss of transcriptional repression by DAX-1 AHC missense mutants and their degree of cytoplasmic localization. Twelve different mutant DAX-1 proteins were investigated. The position of the I439S mutant, whose repression activity is the least impaired, is indicated. $r=0.85$. From [65]. Copyright 2002 National Academy of Sciences, USA.

hormone receptors for interaction with both coactivators and corepressors, which includes a cluster of hydrophobic amino acids surrounded by polar and charged residues localized in helices $\mathrm{H} 3$ and $\mathrm{H} 4[106,107]$. These residues are conserved in DAX-1 and in most other nuclear receptors. For some nuclear receptors, two additional surfaces were shown to be involved in interaction with corepressors, with one lying alongside helix $\mathrm{H} 1$ and the other above helix H11. Mutations in key residues in DAX-1 that are homologous to residues important to mediate interaction of $\operatorname{PPAR} \alpha$ with corepressors [108] had a negative effect on its transcriptional repression activity only when mutations also affected protein expression, without affecting nuclear localization. The only DAX-1 mutation reducing transcriptional repression by about $50 \%$, while keeping a predominantly nuclear localization and expression similar to the wild-type protein, affected S374, a residue predicted to be situated in the loop between helices $\mathrm{H} 7$ and H8 [66].

Particularly interesting to understand the structurefunction relationship in the DAX-1 protein are the mutagenesis studies concerning the predicted C-terminal helix H12. In ligand-activated nuclear receptors, H12 is essential for liganddependent transcriptional activation, repositioning upon ligand binding to stabilize the interaction of coactivator LXXLL motifs with the coactivator-binding surface in the LBD [2]. A critical role in this process is played by a conserved glutamate in $\mathrm{H} 12$, which forms a charge clamp together with a lysine residue localized at the end of helix $\mathrm{H} 3$. $\mathrm{H} 12$ residues required for ligand-dependent transactivation (ФФХЕФФ motif) in other nuclear receptors are conserved in DAX-1. In the mouse
Dax-1 3D structure, helix $\mathrm{H} 12$ is docked in the coactivator groove with the conserved M464, M467, and L468 mimicking the Leu residues from the coactivator LXXLL motif [61]. The docked position of H12 in Dax-1 is then consistent with the protein function as a transcriptional repressor. Additionally, helix $\mathrm{H} 12$ has a critical role in DAX-1 nuclear localization. Deletion of the last four C-terminal amino acids is sufficient to induce a significant shift of the protein to the cytoplasm. Two mutations affecting helix H12 (M461X and L466R) have been found in AHC patients. Those mutations have the effect of completely shifting DAX-1 localization to the cytoplasm, impairing its transcriptional function $[65,66$, 109]. Remarkably, the M461A/M462A double mutant has a predominantly nuclear localization but its repression activity is about $50 \%$ reduced compared to the wild-type protein, indicating that those residues may have an important role in interaction of DAX-1 with corepressors.

The studies on the subcellular distribution of DAX-1 AHC mutants, revealing loss of function of the proteins that cannot enter the nucleus, suggest that regulation of DAX-1 nucleocytoplasmic trafficking may be an important way to modulate its biological activity. Evidence supporting this hypothesis comes from our analysis of DAX-1 distribution during human adrenal development [110]. In the adrenal at the second trimester of gestation, DAX-1 is localized mainly in the nucleus in the outer definitive zone and in the cytoplasm in the fetal zone, whereas the number of DAX-1 positive cells decreases from the external to the internal portion of the gland. DAX-1 nuclear localization in the definitive zone cells is consistent with the negative modulation of steroidogenesis in these cells during the second trimester of gestation. This cell layer represents the proliferative compartment in the human fetal adrenal, while the larger fetal zone cells produce high levels of DHEA/DHEAS. It is then consistent with their function that in fetal zone cells DAX-1 is mainly excluded from the nucleus, where it could act to repress the expression of steroidogenic genes.

Remarkably, DAX-1 subcellular distribution is also influenced by the substrate on which fetal adrenal cells are cultured. On both a collagen and a fibronectin matrix, DAX-1 is localized in the nucleus of the definitive cells and exhibits a nucleocytoplasmic distribution in the fetal cells. ACTH stimulation induces nuclear localization of DAX-1 in fetal cells cultured on collagen, without modifying its nucleocytoplasmic localization in cells cultured on fibronectin. In contrast, angiotensin II induces DAX-1 localization in the cytoplasm in fetal cells, cultured on either collagen or fibronectin, while it does not affect its pattern of distribution in definitive zone cells [110]. These data suggest that modulation of DAX1 localization in the fetal adrenal gland by hormones and components of the extracellular matrix may represent a mechanism for controlling the expression of steroidogenic enzymes in the definitive and fetal zones. This may have a direct impact on the pathogenetic mechanism of AHC. It can be speculated that earlier expression of genes involved in steroid hormone production is activated in adrenal definitive zone cells in individuals carrying a DAX-1 loss-of-function mutant that is unable to appropriately repress steroidogenic genes. Anticipation of the differentiation process in those 
cells may have negative consequences on keeping their stem cell capacities and exhaust the reservoir of adrenocortical progenitor cells. Adrenal hypoplasia would then ensue after the physiological regression of the fetal zone after birth (Figure 3). This hypothesis of progressive exhaustion of adrenal stem cell capacities in the presence of a $D A X-1$ loss-of-function mutation is consistent with data from Dax1 null mice, which display increasingly altered dysplastic adrenal morphology and reduced proliferation in an agedependent fashion. Interestingly, in those animals' adrenals, large eosinophilic cytomegalic cells can be found that are reminiscent of the cytological findings in $\mathrm{X}$-linked human AHC [111].

Another tissue where modulation of DAX-1 subcellular localization may have a role during development is the pituitary gland. Dax-1 is distributed diffusely in both nucleus and cytoplasm in Rathke's pouch cells at E10.5 in the mouse, while at E18.5 it is found localized in the nucleus [109]. Since DAX-1 is able to repress the synergy between Egr- 1 and SF1 in regulating the $\mathrm{LH} \beta$ promoter [112] and SF-1-mediated activation of the nitric oxide synthase gene promoter [113], changes in its subcellular distribution may have a relevant impact on the function of pituitary gonadotrope cells.

Little is known about the mechanisms regulating DAX-1 subcellular distribution. One study showed that heat shock has a dramatic effect on the localization of the DAX-1 protein, completely shifting it to the cytoplasm [114]. DAX1 heat shock-induced cytoplasmic localization is reversible, requires the cooperation of both its $\mathrm{N}$ - and C-terminal domains, and is not sensitive to inhibition of Crm1, p38, and ERK. The heat shock effect on DAX-1 localization is highly specific because other stimulations inducing cellular stress (sorbitol, UV, arsenite, and $\mathrm{H}_{2} \mathrm{O}_{2}$ ) do not affect it. The mechanisms underlying heat shock effect on DAX-1 subcellular localization remain to be determined.

\section{DAX-1 Role in Sex Determination and Gonadal Function: Lessons from DSS Patients and Mouse Models}

During the process of mammalian sex determination, an undifferentiated gonad arises from the intermediate mesoderm. Two ductal structures are present during this bipotential stage, the Wolffian duct, which in the male later differentiates into the epididymis and vas deferens, and the Müllerian duct, which in the female will form the oviducts, uterus, and upper vagina. Transient activation of the Y chromosome testis-determining factor Sry initiates male gonad differentiation by upregulating Sox9. The critical event in sex determination is the formation of Sertoli cells in the male gonad. These cells produce the Müllerian inhibiting substance/anti-Müllerian hormone (MIS/AMH) that produces regression of the Müllerian derivatives in males. In the absence of MIS/AMH production, the female differentiation program of those structures is activated. Once gonadal sex has been determined, the gonad differentiation process follows to give rise to either a mature testis or an ovary.
As mentioned in Section 2, the DAX-1 gene is situated inside the critical region in Xp21 that when duplicated causes DSD of variable severity in 46,XY individuals (DSS) [3]. This region spans 160 kilobases and additionally harbors the MAGEB (MAGEB1-4) family of genes $[115,116]$. Patients with DSS usually bear large chromosomal duplications in the region and have a complex phenotype including mental retardation and other malformations due to a contiguous gene syndrome. However, two 46,XY sisters have been described who carried the same $637 \mathrm{~kb}$ interstitial duplication in Xp21.2 and presented isolated DSD [78]. Based on the DSS phenotype, a role of $D A X-1$ has been investigated in sex determination and differentiation.

As described before in Section 3, a sexually dimorphic expression pattern of Dax-1 during mouse gonadal development was described by Swain et al. [6], with its mRNA reported to be first detectable in the genital ridge at $11.5 \mathrm{dpc}$ and downregulated in the male gonad at later times but remaining expressed at relatively high levels in the developing ovary after E12.5. A subsequent study by the same authors reported that overexpression of a $11 \mathrm{~kb}$ genomic fragment containing the Dax-1 gene induces in some cases hermaphroditism or gonadal female differentiation only in mice from strains harboring a "weak" Sry allele (M. domesticus poschiavinus XY animals, Sry transgenic XX animals) [117]. These data, together with the human DSS syndrome phenotype, led to the hypothesis that $D A X-1$ represents an "antitestis" gene, antagonizing Sry function and required for ovarian differentiation [118]. However, ovaries were present in a female patient affected with HHG and homozygote for a $D A X-1$ nonsense mutation [91]. Also in contrast with the results by Swain et al., as described before in Section 3, several other studies showed that the Dax-1 transcript is expressed at equivalent levels in mouse and rat testis and ovary at E12.5-E15.5, while it is downregulated in the ovary at later times $[15,16]$. The Dax-1 protein is expressed in the mouse testis Sertoli and Leydig cells and throughout the ovarian primordium at E12.5-E14.5 [17]. Furthermore, in humans $D A X-1$ is expressed both in the male and the female embryonic gonads during the critical period of sex determination [22]. It is also worth to be mentioned that $D A X-1$ homologues are expressed during embryogenesis in the gonads of both sexes in another mammalian species (pig) and in chicken, frog, and fish [7, 8, 10, 11]. Moreover, in alligator and turtle species where sexual differentiation is determined by temperature, Dax-1 is expressed at similar levels in male and female gonads during the critical period for their specification $[9,12]$. Taken together, all these results argue against the previously advanced model that a sexual dimorphism of Dax-1 expression during gonad development is required for ovarian differentiation and rather suggest that this transcription factor has a specific function in different cell types in both sexes. More recent studies showed that Dax1 is essential for male but is dispensable for female gonadal development. In the mouse knockout model (obtained by Cre recombinase-mediated deletion of the Dax-1 exon 2), which in other respects presents neither an adrenal hypoplasia nor a hypogonadotropic phenotype, Dax-1 is required for normal testis morphology and function. Dax -1 inactivation 


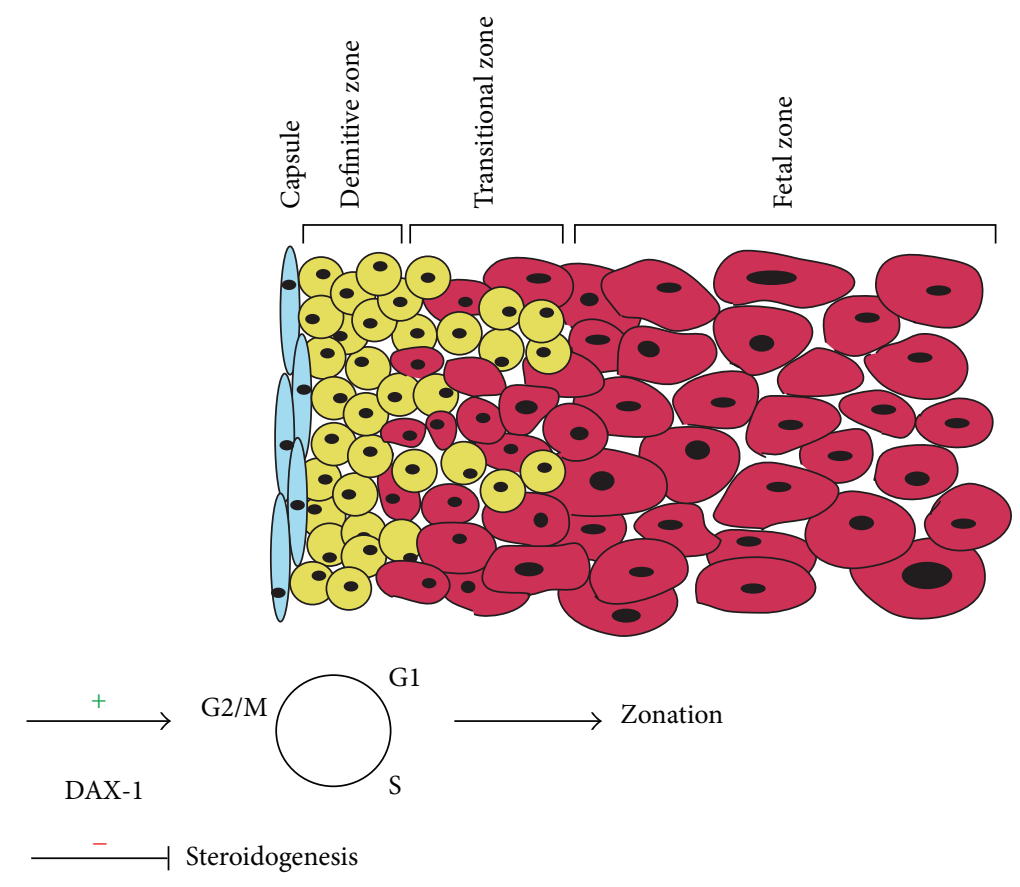

FIGURE 3: A model of DAX-1 function during human adrenal development. DAX-1 represses steroidogenic gene expression in definitive zone cells, allowing for their proliferation and differentiation into glomerulosa, fasciculata, and reticularis zones. In the absence of functional DAX-1, abnormally early expression of steroidogenic genes is activated in the definitive zone and its proliferation is downregulated. Under these conditions, adrenal hypoplasia follows the physiological regression of the fetal zone after birth. From [35]. Copyright 2003 Endocrine Society.

causes progressive degeneration of the testicular germinal epithelium and dilation of the seminiferous tubules with the concomitant Leydig cell hyperplasia, resulting in male sterility already at a young age $[119,120]$. Conversely, Dax1 null females have normal ovarian development and are fertile; the only abnormality detectable in their ovaries is that a subset of follicles harbors multiple oocytes. In male Dax1 null mice, independent transgenic reexpression of Dax-1 in Sertoli and Leydig cells, respectively, improved fertility, but not testicular pathology, showing that the testicular phenotype of those mice reflects the combined effects of Dax-1 deficiency in both cell types $[121,122]$. An interesting finding was that in the testis of Dax-1 null mice the ectopic Sertoli and Leydig cells block the rete testis and the efferent ductules, with sex-cord stromal tumors being present in about one-third of aged animals [123]. A critical molecular abnormality present in the testes of Dax-1 null males is upregulation of aromatase expression in Leydig cells, with consequent increased intratesticular estradiol levels [124]. Strikingly, Leydig cell hyperplasia and fertility in Dax-1 null males could be rescued by tamoxifen (a selective estrogen receptor modulator) administration, showing that estrogen excess is important to impair testicular function in those animals. It was shown that Sv/129 Dax-1 null mice have a defect in testis cord formation during development with a lower number of peritubular myoid cells and disruption of the basal lamina [120]. The severity of testicular defects in Dax-1 null mice depends on the genetic background, since Dax-1 deficiency can even induce gonadal sex reversal in the poschiavinus and C57BL/6J strains, associated with a defect in Sox9 upregulation in Sertoli cells $[125,126]$. Interestingly, Dax-1 inactivation does not compensate for the defects present in the testes of $S f-1$ heterozygote mice but further impairs Sertoli cell differentiation and fetal Leydig cell differentiation [127]. These data show that early male gonadal development in mice depends on the cooperative function of both $S f-1$ and Dax-1 (see also Section 4).

Consistent with the role of Dax-1 in testicular development in mice, a primary testicular defect is present in $D A X$ 1 mutation carriers, since in these subjects gonadotropin treatment is not able to normalize spermatogenesis and testicular biopsy shows disorganization of seminiferous tubular structure and Leydig cell hyperplasia [128]. An interesting possibility for these patients to father children is to undergo in vitro fertilization of oocytes using sperm recovered from testicular biopsies, as described in a recent report [94] (see Section 6).

Even if caution should be taken to interpret the results generated in transgenic mice [117], as discussed before, $D A X$ 1 remains the best candidate gene inside the DSS critical interval to produce female or ambiguous gonadal differentiation in XY individuals carrying duplications of the Xp21 region because of its known transcriptional repressor activity. Different mechanisms may be responsible for the effect of 
an increased DAX-1 dosage on gonadal differentiation as follows.

(1) Repression of MIS/AMH production by fetal Sertoli cells. Dax-1 antagonizes the synergy between SF-1 and WT1 in activating the MIS/AMH gene promoter, consistent with its role as a general negative regulator of SF-1-induced transactivation [16]. DAX-1 overexpression would then lead to repression of MIS/AMH expression producing persistence of the Müllerian derivatives, as observed in some DSS patients [3].

(2) Repression of testosterone production by fetal Leydig cells. Considering its negative effect on steroidogenesis [21,31,32], DAX-1 overexpression would inappropriately repress testosterone biosynthesis in fetal Leydig cells, which is essential for sexual secondary character masculinization.

(3) An increased Dax-1 dosage may inhibit activation of the Sox 9 testis enhancer by SF-1, as suggested recently [129]. However, in that study the reduction of Sox9 mRNA expression in XY Dax-1 transgenic gonads compared to wild type was not statistically significant. The relative importance of this mechanism to produce the DSS phenotype then warrants further investigation.

\section{Dax-1 in Stem Cells and Cancer}

ES cells are characterized by their self-renewing (capacity to undergo cell division without differentiation) and pluripotency (capacity to give rise to cells belonging to all three germ layers: ectoderm, endoderm, and mesoderm) properties. Their pluripotent state is maintained by the action of multiple signaling pathways and transcription factors, with a pivotal role played by the POU domain factor Oct3/4 and the Nanog homeoprotein [130]. These factors orchestrate transcriptional regulatory networks whose integrity is crucial to keep the pluripotent state of ES cells. It has been shown that it is possible to produce pluripotent stem cells derived from differentiated cells by inducing a forced expression of specific genes (induced pluripotent stem cells (iPSCs)) [131].

The identification of Dax-1 expression and role in mouse ES cells has opened a whole new field of investigation. Dax1 is expressed at high levels in mouse ES cells (Figure 4(a)) [132] and its knockdown or gene inactivation by homologous recombination induces loss of their pluripotency and differentiation [133]. Further studies have shown that Dax-1 is part of the core protein network implicated in the homeostasis of mouse ES cells pluripotency and self-renewal, by interacting with other essential pluripotency factors and binding to a common set of promoters [134-136].

In mouse ES cells, Dax-1 expression is controlled by the pluripotency factors STAT3, Oct3/4, Nanog, and Esrrb $[57,134,137]$. In turn, Dax-1 binds to Oct3/4 and inhibits its transcriptional activity, thus establishing a regulatory circuit limiting Oct3/4 activity in ES cells $[58,138]$. This may be an important mechanism for Dax-1 to sustain ES cell pluripotency, since excessive Oct $3 / 4$ activity leads to their differentiation [139]. Also, Dax-1 overexpression is able to induce ES cells differentiation [137]. Another report suggested that Dax-1 may upregulate nuclear receptor LRH1-mediated Oct $3 / 4$ expression in mouse ES cells through interaction with the RNA coactivator SRA (see Section 4) [75]. However, other studies did not confirm the direct positive transcriptional effect of Dax- 1 on Oct $3 / 4$ expression $[137,140]$. Furthermore, Dax-1 has also been reported to interact with the other pluripotency factors Nanog [135] and Esrrb [57]. In a study investigating binding to gene promoters for nine transcription factors (including Dax-1) involved in the keeping of the pluripotency state in mouse ES cells, Kim et al. identified a common set of promoters bound by multiple factors [136]. Those authors correlated the probability that a given gene is expressed in pluripotent ES cells and repressed after their differentiation with the number of pluripotency factors bound at the level of its promoter.

Dax-1 expression is controlled by the $\beta$-catenin pathway in mouse ES cells and its knockdown induces rapid upregulation of genes expressed in the three embryonic germ layers and cell differentiation [140]. Similarly to steroidogenic cells, also in mouse ES cells Dax-1 functions as a transcriptional repressor. Consistently with this activity, Dax-1 knockdown increases the expression of more than $90 \%$ of the genes that it regulates (Figure 4(b)). Those genes are involved in the differentiation of multiple tissues and also in the control of cell proliferation and apoptosis [140]. These results are not consistent with previous studies which had suggested an "additive" model for gene regulation in mouse ES cells, with promoters bound by multiple factors being active in pluripotent cells and then repressed upon differentiation [136]. This rather simplistic model of gene regulation should then be modified to take into account the specific role of Dax-1, which has probably a specialized function to repress the expression of a specific subset of genes involved in differentiation of mouse ES cells, thus playing a critical function in the preservation of their pluripotency. Therefore, we have suggested that Dax-1 is not to be considered as an essential pluripotency factor in murine ES cells but rather as a specialized pluripotency keeper that is hierarchically situated between upstream bona fide pluripotency factors and downstream differentiation genes with the task of repressing the expression of a specific subset among them [140, 141]. Consistent with this hypothesis, it is interesting to remark that Dax-1 is not able to enhance reprogramming of fibroblasts into iPSCs or to replace any of the reprogramming factors [142].

In contrast to mouse ES cells, DAX-1 is only expressed at very low levels in human ES cells and its expression is inconsistently modulated during their differentiation [143]. These data suggest that the important role played by Dax1 in the pluripotency mechanism in mouse ES cells is not conserved or that redundant pathways may be active. This is consistent with the fact that individuals carrying loss-offunction mutations in $D A X-1$ are born to term, even if they may eventually develop AHC/HHG. On the other hand, it is conceivable that in humans the function of DAX-1 in stem cells maintenance became restricted only to some tissues (like the adrenal cortex) and may be brought back to life 


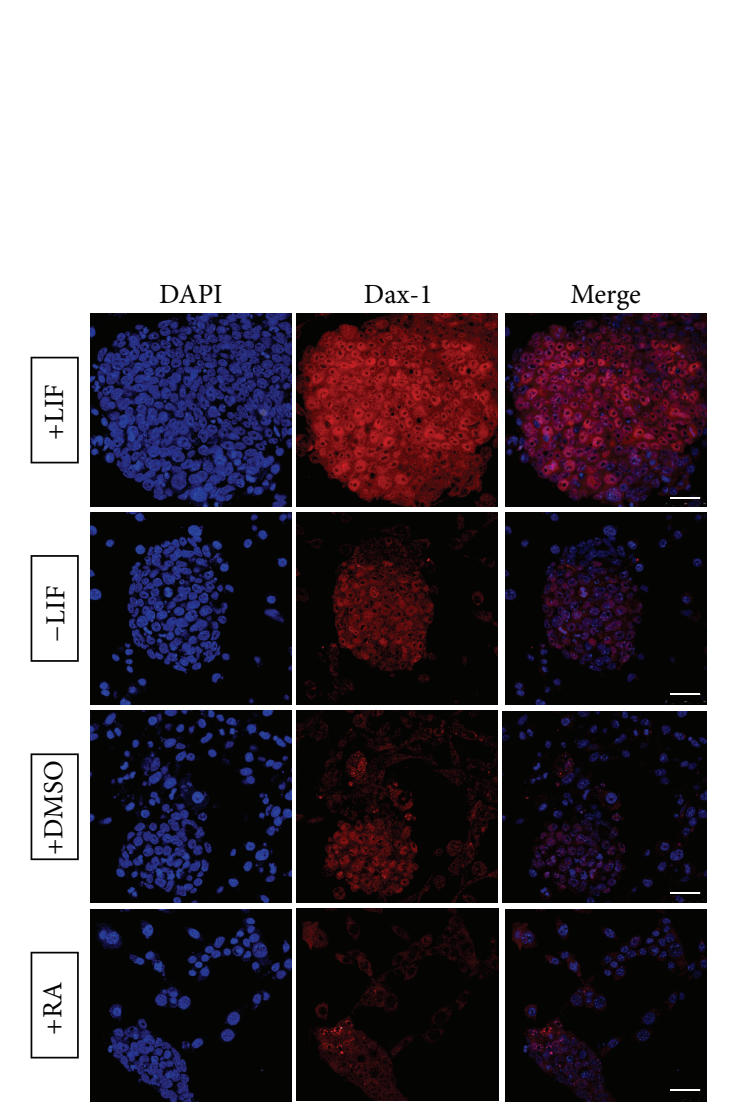

(a)

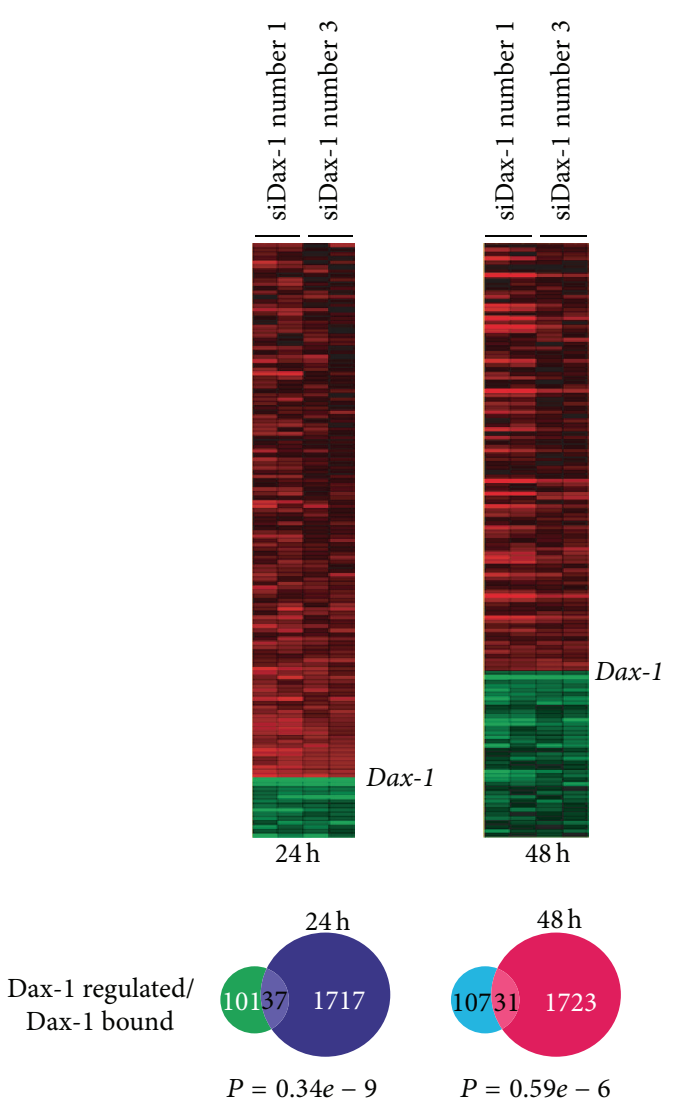

(b)

Figure 4: Expression of Dax-1 in mouse ES cells and effects of its knockdown on gene expression profiles. (a) Immunofluorescence showing Dax-1 expression in mouse ES cells grown in the presence of LIF (+LIF) or subjected to different differentiation protocols for 48 hours: culture in the absence of LIF (-LIF), without LIF + 1\% DMSO (+DMSO), and treatment with $2 \mu \mathrm{M}$ RA (+RA). Nuclei were counterstained with DAPI dye and images were acquired by confocal microscopy. Scale bar $=50 \mu \mathrm{m}$. DAPI: 4',6-diamidino-2-phenylindole; DMSO: dimethyl sulfoxide; LIF: leukemia inhibitory factor; RA: retinoic acid. (b) Top: unsupervised clustering of genes regulated by Dax-1 knockdown in mouse ES cells using two different Dax-1 specific siRNAs (siDax-1 number 1 and siDax-1 number 3). In red, genes upregulated by Dax-1 knockdown; in green, genes downregulated by Dax-1 knockdown. Left panel: genes regulated for 24 hours after siRNA transfection; right panel: genes regulated for 48 hours after siRNA transfection. Bottom: comparison of genes regulated by Dax-1 knockdown at 24 (left) and 48 (right) hours with genes bound by Dax-1 in the study by Kim et al. [136]. From [140]. Copyright 2009 John Wiley \& Sons.

in some cancer types (see below). Intriguingly, evidence for Dax-1 being involved in inhibiting premature differentiation of adrenal stem cells comes from a recent study showing establishment of adrenal insufficiency and development of adrenocortical dysplasia in aged Dax-1 null mice after an early phase of hyperfunction, probably as a consequence of depletion of the adrenal stem cell pool [111].

The first studies analyzing $D A X-1$ expression in tumors concerned adrenocortical neoplasms. Similarly to other welldescribed situations, the levels of $D A X-1$ expression and hormone production are inversely correlated in benign adrenocortical adenomas (with $D A X-1$ levels being the lowest in aldosterone-producing adenomas, intermediate in cortisolproducing adenomas, and the highest in nonfunctioning adenomas), while its expression in adrenocortical carcinomas is highly variable [144]. Other studies also showed low $D A X$ 1 levels in cortisol-producing adenomas but elevated expression in two cases of the rare deoxycorticosterone-producing adenomas [145]. These studies suggest then that DAX-1 expression may influence the pattern of steroids produced by the tumors. In addition, DAX-1 may have an important role in adrenocortical tumors to limit SF-1 transcriptional activity, whose increased dosage has been linked to increased cell proliferation and adrenocortical tumor formation in mice [41].

More recently, $D A X-1$ expression has been reported and correlated with clinical parameters in different types of human tumors derived from a variety of tissues (reviewed in [141]). An important caveat, however, must be taken into account when considering the published studies about $D A X-1$ expression in cancer. The commercial antibody used in most of the studies mentioned below does not specifically recognize DAX-1 either in immunohistochemistry or immunoblotting [146, 147]. This obviously engenders considerable uncertainty in the interpretation of the results obtained in those studies. 
8.1. Pituitary Adenomas. DAX-1 is coexpressed with SF-1 in pituitary adenomas of gonadotropic origin (nonfunctioning) [148]. DAX-1 is also expressed in some somatotroph tumors. No relationship appears to exist between DAX-1 expression and $\mathrm{FSH} / \alpha \mathrm{GSU}$ production in vitro by cell cultures from pituitary adenomas [149].

8.2. Ovarian Carcinoma. DAX-1 immunoreactivity correlates in a direct fashion with clinical staging, tumor grade, residual size of the tumor after neoadjuvant chemotherapy, and its Ki-67 labeling index and inversely with survival [150].

8.3. Breast Cancer. DAX-1 immunoreactivity was reported to be directly correlated with androgen receptor expression and nodal status [151].

8.4. Endometrial Carcinoma. DAX-1 immunoreactivity correlated inversely with histological grade and positively with $\mathrm{ER} \alpha$ and $\mathrm{ER} \beta$ expression [152].

8.5. Prostate Cancer. DAX-1 immunoreactivity correlated inversely with Gleason score, a grading system used to assess malignancy in this type of cancer [153].

8.6. Lung Cancer. A gene expression profiling study showed that DAX-1 expression is high in lung adenocarcinoma cancer stem cells identified in the A549 cell line as a side population (SP) by flow cytometry [154]. Only SP cells are tumorigenic when injected in nude mice. These data suggest that, similarly to its role in mouse ES cells, DAX-1 may be involved in the maintenance of cancer stem cells in lung adenocarcinoma. Another study showed that $D A X-1$ knockdown does not increase proliferation of A549 cells but increases their sensitivity to the topoisomerase I inhibitor topotecan and decreases their invasive ability in a Matrigel invasion assay, colony formation in vitro, and xenograft growth in immunodeficient mice [155]. In addition, higher levels of DAX-1 expression in lung adenocarcinoma correlated with high rates of lymph node metastasis and recurrence. At least in some cases, high DAX-1 expression in lung adenocarcinoma may be determined by demethylation of its promoter. Importantly, disease-free and overall survival were significantly better in lung adenocarcinoma patients with low DAX-1 expression in the tumor compared with patients displaying high DAX1 expression. In multivariate analysis high DAX-1 expression levels were an independent unfavorable prognostic factor, together with stage of the disease and size of tumor [155]. Even if these results need to be confirmed on a larger cohort of patients, they lay the groundwork for further studies on the role of DAX-1 in lung cancer, with possible therapeutic applications.

8.7. Ewing Tumors and Other Soft Tissue Tumors. This is the type of cancer where the mechanisms regulating $D A X-1$ expression and its role in cancer cell biology are at present best known. Ewing tumors represent a group of highly malignant bone and soft tissue tumors usually diagnosed in children, adolescents, and young adults. They are associated with specific balanced chromosomal translocations, leading to the expression of chimeric proteins harboring the $\mathrm{N}$ terminal region of the EWS gene product and the C-terminal region of a member of the ETS family of transcription factors, most commonly FLI1. Those fusion oncogenes have a pathogenetic role in the disease by regulating the transcription of specific target genes in cancer cells [156].

$D A X-1$ is specifically expressed and is required for the oncogenic phenotype in Ewing tumors, but not in other histologically similar small round cell tumors, as neuroblastoma and embryonal rhabdomyosarcoma [157, 158]. However, $D A X-1$ was found expressed in cases of rhabdomyosarcoma of the alveolar subtype bearing a PAX3, or PAX7, containing fusion protein together with FKHR [157] and is one of the genes whose expression allows for discrimination between embryonal and alveolar rhabdomyosarcoma [159].

In Ewing tumors, the EWS/FLI1 oncoprotein directly regulates $D A X-1$ expression by binding to a polymorphic GGAA-rich region in its promoter [160, 161]. Moreover, $D A X-1$ expression levels in Ewing tumor cell lines correlated positively with the number of GGAA repeats present in their DAX-1 promoter. DAX-1 was also reported to physically interact with and modulate the transcriptional activity of the EWS/FLI1 oncoprotein [59]. DAX-1 has an important role in regulating Ewing tumor cells growth since its knockdown blocks cell proliferation in vitro, causing accumulation in the G1 phase of the cell cycle, and significantly impairs the growth of Ewing tumor cells grafted in immunodeficient mice [160]. Importantly, the effect of $D A X-1$ knockdown on Ewing tumor cells proliferation was observed in the presence of continued expression of the EWS/FLI-1 oncoprotein, indicating the main role of DAX-1 in mediating EWS/FLI1 effects. Consistently with these results, analysis of gene expression profiles showed that the expression of about $10 \%$ of the genes regulated by EWS/FLI1 in Ewing tumor cells is sensitive to $D A X-1$ knockdown. Genes involved in cell cycle control, and more specifically genes implicated in the G1/S transition such as CDK2, SKP2, MCM10, and CDC6, are significantly enriched among DAX-1 target genes in Ewing tumor cells [160]. Altogether, these results show that $D A X-1$ plays an essential role in the generation of the transformed phenotype of Ewing tumor cells and suggest that it may be a novel therapeutic target in this disease.

\section{Conclusions}

Twenty years have elapsed since the cloning of the $D A X$ 1 gene and much progress has been made to elucidate the pathogenetic mechanisms of AHC, the role of DAX1 in the control of steroidogenesis and gonadal function and its unexpected involvement in stem cell biology and cancer. However, this unusual nuclear receptor still keeps many of its secrets, especially concerning its mechanisms of transcriptional regulation and the identity of its target genes during development, in adult tissues and in pathological conditions. New efforts are eagerly needed to understand its function in physiology and disease using a combination of cell biology, structural and genomic approaches, together 
with the production of novel animal models and the integration of results from clinical studies.

\section{Conflict of Interests}

The author declares that there is no conflict of interests regarding the publication of this paper.

\section{Acknowledgment}

The author thanks B. Bardoni for introducing him to $D A X-1$.

\section{References}

[1] D. J. Mangelsdorf, C. Thummel, M. Beato et al., "The nuclear receptor super-family: the second decade," Cell, vol. 83 , no. 6 , pp. 835-839, 1995.

[2] J. M. Wurtz, W. Bourguet, J. P. Renaud et al., "A canonical structure for the ligand-binding domain of nuclear receptors," Nature Structural Biology, vol. 3, no. 1, pp. 87-94, 1996.

[3] B. Bardoni, E. Zanaria, S. Guioli et al., "A dosage sensitive locus at chromosome Xp21 is involved in male to female sex reversal," Nature Genetics, vol. 7, no. 4, pp. 497-501, 1994.

[4] E. Zanaria, F. Muscatelli, B. Bardoni et al., "An unusual member of the nuclear hormone receptor superfamily responsible for Xlinked adrenal hypoplasia congenita," Nature, vol. 372, no. 6507, pp. 635-641, 1994.

[5] F. Muscatelli, T. M. Strom, A. P. Walker et al., "Mutations in the $D A X-1$ gene give rise to both $\mathrm{X}$-linked adrenal hypoplasia congentia and hypogonadotropic hypogonadism," Nature, vol. 372 , no. 6507, pp. 672-676, 1994.

[6] A. Swain, E. Zanaria, A. Hacker, R. Lovell-Badge, and G. Camerino, "Mouse Daxl expression is consistent with a role in sex determination as well as in adrenal and hypothalamus function," Nature Genetics, vol. 12, no. 4, pp. 404-409, 1996.

[7] P. Parma, E. Pailhoux, C. Puissant, and C. Cotinot, "Porcine Dax-1 gene: isolation and expression during gonadal development," Molecular and Cellular Endocrinology, vol. 135, no. 1, pp. 49-58, 1997.

[8] C. A. Smith, V. Clifford, P. S. Western, S. A. Wilcox, K. S. Bell, and A. H. Sinclair, "Cloning and expression of a DAX1 homologue in the chicken embryo," Journal of Molecular Endocrinology, vol. 24, no. 1, pp. 23-32, 2000.

[9] P. S. Western, J. L. Harry, J. A. Marshall Graves, and A. H. Sinclair, "Temperature-dependent sex determination in the American alligator: expression of $S F 1, W T 1$ and $D A X 1$ during gonadogenesis," Gene, vol. 241, no. 2, pp. 223-232, 2000.

[10] J. Sugita, M. Takase, and M. Nakamura, "Expression of Dax-1 during gonadal development of the frog," Gene, vol. 280, no. 12, pp. 67-74, 2001.

[11] D.-S. Wang, T. Kobayashi, B. Senthilkumaran et al., "Molecular cloning of DAX1 and SHP cDNAs and their expression patterns in the Nile tilapia, Oreochromis niloticus," Biochemical and Biophysical Research Communications, vol. 297, no. 3, pp. 632640, 2002.

[12] L. C. Torres Maldonado, A. Landa Piedra, N. Moreno Mendoza, A. Marmolejo Valencia, A. Meza Martínez, and H. Merchant Larios, "Expression profiles of Dax1, Dmrt1, and Sox9 during temperature sex determination in gonads of the sea turtle Lepidochelys olivacea," General and Comparative Endocrinology, vol. 129, no. 1, pp. 20-26, 2002.
[13] W. Seol, H. S. Choi, and D. D. Moore, "An orphan nuclear hormone receptor that lacks a DNA binding domain and heterodimerizes with other receptors," Science, vol. 272, pp. 1336-1339, 1996.

[14] A. Ehrlund and E. Treuter, "Ligand-independent actions of the orphan receptors/corepressors DAX-1 and SHP in metabolism, reproduction and disease," The Journal of Steroid Biochemistry and Molecular Biology, vol. 130, pp. 169-179, 2012.

[15] Y. Ikeda, A. Swain, T. Weber et al., "Steroidogenic factor 1 and Dax-1 colocalize in multiple cell lineages: potential links in endocrine development," Molecular Endocrinology, vol. 10, pp. 1261-1272, 1996.

[16] M. W. Nachtigal, Y. Hirokawa, D. L. Enyeart-VanHouten, J. N. Flanagan, G. D. Hammer, and H. A. Ingraham, "Wilms' tumor 1 and Dax-1 modulate the orphan nuclear receptor SF-1 in sexspecific gene expression," Cell, vol. 93, no. 3, pp. 445-454, 1998.

[17] Y. Ikeda, Y. Takeda, T. Shikayama, T. Mukai, S. Hisano, and K.-I. Morohashi, "Comparative localization of Dax-1 and Ad4BP/SF1 during development of the hypothalamic-pituitary-gonadal axis suggests their closely related and distinct functions," Developmental Dynamics, vol. 220, no. 4, pp. 363-376, 2001.

[18] T. Mukai, M. Kusaka, K. Kawabe et al., "Sexually dimorphic expression of Dax-1 in the adrenal cortex," Genes to Cells, vol. 7, no. 7, pp. 717-729, 2002.

[19] K. T. Tamai, L. Monaco, T. P. Alastalo, E. Lalli, M. Parvinen, and P. Sassone-Corsi, "Hormonal and developmental regulation of DAX-1 expression in Sertoli cells," Molecular Endocrinology, vol. 10, no. 12, pp. 1561-1569, 1996.

[20] S. Mesiano and R. B. Jaffe, "Developmental and functional biology of the primate fetal adrenal cortex," Endocrine Reviews, vol. 18, pp. 378-403, 1997.

[21] N. A. Hanley, W. E. Rainey, D. I. Wilson, S. G. Ball, and K. L. Parker, "Expression profiles of SF-1, DAX1, and CYP17 in the human fetal adrenal gland: potential interactions in gene regulation," Molecular Endocrinology, vol. 15, no. 1, pp. 57-68, 2001.

[22] N. A. Hanley, D. M. Hagan, M. Clement-Jones et al., " $S R Y$, $S O X 9$, and DAX1 expression patterns during human sex determination and gonadal development," Mechanisms of Development, vol. 91, no. 1-2, pp. 403-407, 2000.

[23] X. Luo, Y. Ikeda, and K. L. Parker, "A cell-specific nuclear receptor is essential for adrenal and gonadal development and sexual differentiation,” Cell, vol. 77, no. 4, pp. 481-490, 1994.

[24] K. L. Parker and B. P. Schimmer, "Steroidogenic factor 1: a key determinant of endocrine development and function," Endocrine Reviews, vol. 18, pp. 361-377, 1997.

[25] Y. Ikeda, W.-H. Shen, H. A. Ingraham, and K. L. Parker, "Developmental expression of mouse steroidogenic factor-1, an essential regulator of the steroid hydroxylases," Molecular Endocrinology, vol. 8, no. 5, pp. 654-662, 1994.

[26] I. N. Krylova, E. P. Sablin, J. Moore et al., "Structural analyses reveal phosphatidyl inositols as ligands for the NR5 orphan receptors SF-1 and LRH-1," Cell, vol. 120, no. 3, pp. 343-355, 2005.

[27] Y. Li, M. Choi, G. Cavey et al., "Crystallographic identification and functional characterization of phospholipids as ligands for the orphan nuclear receptor steroidogenic factor-1," Molecular Cell, vol. 17, no. 4, pp. 491-502, 2005.

[28] W. Wang, C. Zhang, A. Marimuthu et al., "The crystal structures of human steroidogenic factor-1 and liver receptor homologue1," Proceedings of the National Academy of Sciences of the United States of America, vol. 102, no. 21, pp. 7505-7510, 2005. 
[29] M. Ito, R. Yu, and J. L. Jameson, " $D A X-1$ inhibits SF-1-mediated transactivation via a carboxy-terminal domain that is deleted in adrenal hypoplasia congenita," Molecular and Cellular Biology, vol. 17, pp. 1476-1483, 1997.

[30] E. Lalli, B. Bardoni, E. Zazopoulos et al., "A transcriptional silencing domain in $D A X-1$ whose mutation causes adrenal hypoplasia congenita," Molecular Endocrinology, vol. 11, no. 13, pp. 1950-1960, 1997.

[31] E. Zazopoulos, E. Lalli, D. M. Stocco, and P. Sassone-Corsi, "DNA binding and transcriptional repression by DAX-1 blocks steroidogenesis," Nature, vol. 390, no. 6657, pp. 311-315, 1997.

[32] E. Lalli, M. H. Melner, D. M. Stocco, and P. SassoneCorsi, "DAX-1 blocks steroid production at multiple levels," Endocrinology, vol. 139, no. 10, pp. 4237-4243, 1998.

[33] B. Ragazzon, A.-M. Lefrançois-Martinez, P. Val et al., "Adrenocorticotropin-dependent changes in SF-1/DAX-1 ratio influence steroidogenic genes expression in a novel model of glucocorticoid-producing adrenocortical cell lines derived from targeted tumorigenesis," Endocrinology, vol. 147, no. 4, pp. 1805-1818, 2006.

[34] P. S. Babu, D. L. Bavers, F. Beuschlein et al., "Interaction between Dax-1 and steroidogenic factor-1 in vivo: increased adrenal responsiveness to ACTH in the absence of Dax-1," Endocrinology, vol. 143, no. 2, pp. 665-673, 2002.

[35] E. Lalli and P. Sassone-Corsi, " $D A X-1$, an unusual orphan receptor at the crossroads of steroidogenic function and sexual differentiation," Molecular Endocrinology, vol. 17, no. 8, pp. 1445-1453, 2003.

[36] A. Ehrlund, E. Holter Anthonisen, N. Gustafsson et al., "E3 ubiquitin ligase RNF31 cooperates with $D A X-1$ in transcriptional repression of steroidogenesis," Molecular and Cellular Biology, vol. 29, no. 8, pp. 2230-2242, 2009.

[37] T. P. Burris, W. Guo, T. Le, and E. R. B. McCabe, "Identification of a putative steroidogenic factor-1 response element in the DAX-1 promoter," Biochemical and Biophysical Research Communications, vol. 214, no. 2, pp. 576-581, 1995.

[38] E. Vilain, W. Guo, Y. H. Zhang, and E. R. McCabe, “DAX1 gene expression upregulated by steroidogenic factor 1 in an adrenocortical carcinoma cell line," Biochemical and Molecular Medicine, vol. 61, no. 1, pp. 1-8, 1997.

[39] K. Kawabe, T. Shikayama, H. Tsuboi et al., "Dax-1 as one of the target genes of Ad4BP/SF-1," Molecular Endocrinology, vol. 13, no. 8, pp. 1267-1284, 1999.

[40] C. Hoyle, V. Narvaez, G. Alldus, R. Lovell-Badge, and A. Swain, "Dax1 expression is dependent on steroidogenic factor 1 in the developing gonad," Molecular Endocrinology, vol. 16, no. 4, pp. 747-756, 2002.

[41] M. Doghman, T. Karpova, G. A. Rodrigues et al., "Increased steroidogenic factor-1 dosage triggers adrenocortical cell proliferation and cancer," Molecular Endocrinology, vol. 21, no. 12, pp. 2968-2987, 2007.

[42] M. Doghman, B. C. Figueiredo, M. Volante, M. Papotti, and E. Lalli, "Integrative analysis of SF-1 transcription factor dosage impact on genome-wide binding and gene expression regulation," Nucleic Acids Research, vol. 41, no. 19, pp. 8896-8907, 2013.

[43] E. Lalli, M. Doghman, P. Latre de Late, A. El Wakil, and I. MusVeteau, "Beyond steroidogenesis: novel target genes for SF-1 discovered by genomics," Molecular and Cellular Endocrinology, vol. 371, no. 1-2, pp. 154-159, 2013.

[44] M. Zubair, K. L. Parker, and K.-I. Morohashi, "Developmental links between the fetal and adult zones of the adrenal cortex revealed by lineage tracing," Molecular and Cellular Biology, vol. 28, no. 23, pp. 7030-7040, 2008.

[45] T. Suzuki, M. Kasahara, H. Yoshioka, K.-I. Morohashi, and K. Umesono, "LXXLL-related motifs in Dax-1 have target specificity for the orphan nuclear receptors Ad4BP/SF-1 and LRH-1," Molecular and Cellular Biology, vol. 23, no. 1, pp. 238249, 2003.

[46] H. Zhang, J. S. Thomsen, L. Johansson, J.-Å. Gustafsson, and E. Treuter, "DAX-1 functions as an LXXLL-containing corepressor for activated estrogen receptors," The Journal of Biological Chemistry, vol. 275, no. 51, pp. 39855-39859, 2000.

[47] E. Holter, N. Kotaja, S. Mäkela et al., "Inhibition of androgen receptor (AR) function by the reproductive orphan nuclear receptor DAX-1," Molecular Endocrinology, vol. 16, no. 3, pp. 515-528, 2002.

[48] I. U. Agoulnik, W. C. Krause, W. E. Bingman III et al., "Repressors of androgen and progesterone receptor action," The Journal of Biological Chemistry, vol. 278, no. 33, pp. 31136-31148, 2003.

[49] K.-H. Song, Y.-Y. Park, K. C. Park et al., "The atypical orphan nuclear receptor $D A X-1$ interacts with orphan nuclear receptor Nur77 and represses its transactivation," Molecular Endocrinology, vol. 18, no. 8, pp. 1929-1940, 2004.

[50] Y.-Y. Park, S.-W. Ahn, H.-J. Kim et al., "An autoregulatory loop controlling orphan nuclear receptor $D A X-1$ gene expression by orphan nuclear receptor ERR $\gamma$," Nucleic Acids Research, vol. 33, no. 21, pp. 6756-6768, 2005.

[51] J. Zhou, R. H. Oakley, and J. A. Cidlowski, “DAX-1 (dosagesensitive sex reversal-adrenal hypoplasia congenita critical region on the $\mathrm{X}$-chromosome, gene 1) selectively inhibits transactivation but not transrepression mediated by the glucocorticoid receptor in a LXXLL-dependent manner," Molecular Endocrinology, vol. 22, no. 7, pp. 1521-1534, 2008.

[52] G. S. Kim, G. Y. Lee, B. Nedumaran et al., “The orphan nuclear receptor $D A X-1$ acts as a novel transcriptional corepressor of PPAR $\gamma$," Biochemical and Biophysical Research Communications, vol. 370, no. 2, pp. 264-268, 2008.

[53] B. Nedumaran, S. Hong, Y.-B. Xie et al., " $D A X-1$ acts as a novel corepressor of orphan nuclear receptor $\mathrm{HNF} 4 \alpha$ and negatively regulates gluconeogenic enzyme gene expression," The Journal of Biological Chemistry, vol. 284, no. 40, pp. 27511-27523, 2009.

[54] B. Nedumaran, G. S. Kim, S. Hong et al., "Orphan nuclear receptor $D A X-1$ acts as a novel corepressor of liver $\mathrm{X}$ receptor $\alpha$ and inhibits hepatic lipogenesis," The Journal of Biological Chemistry, vol. 285, no. 12, pp. 9221-9232, 2010.

[55] J. Li, Y. Lu, R. Liu et al., "DAX1 suppresses FXR transactivity as a novel co-repressor," Biochemical and Biophysical Research Communications, vol. 412, no. 4, pp. 660-666, 2011.

[56] E. M. Laurenzana, T. Chen, M. Kannuswamy et al., "The orphan nuclear receptor $D A X-1$ functions as a potent corepressor of the constitutive androstane receptor (NR1I3)," Molecular Pharmacology, vol. 82, no. 5, pp. 918-928, 2012.

[57] K. Uranishi, T. Akagi, C. Sun, H. Koide, and T. Yokota, “Dax1 associates with Esrrb and regulates its function in embryonic stem cells," Molecular and Cellular Biology, vol. 33, no. 10, pp. 2056-2066, 2013.

[58] C. Sun, Y. Nakatake, T. Akagi et al., "Dax1 binds to Oct3/4 and inhibits its transcriptional activity in embryonic stem cells," Molecular and Cellular Biology, vol. 29, no. 16, pp. 4574-4583, 2009.

[59] M. Kinsey, R. Smith, A. K. Iyer, E. R. B. McCabe, and S. L. Lessnick, "EWS/FLI and its downstream target NROB1 interact 
directly to modulate transcription and oncogenesis in Ewing's sarcoma," Cancer Research, vol. 69, no. 23, pp. 9047-9055, 2009.

[60] P. R. Manna, M. T. Dyson, Y. Jo, and D. M. Stocco, "Role of dosage-sensitive sex reversal, adrenal hypoplasia congenita, critical region on the $\mathrm{x}$ chromosome, gene 1 in protein kinase aand protein kinase c-mediated regulation of the steroidogenic acute regulatory protein expression in mouse leydig tumor cells: mechanism of action," Endocrinology, vol. 150, no. 1, pp. 187-199, 2009.

[61] E. P. Sablin, A. Woods, I. N. Krylova, P. Hwang, H. A. Ingraham, and R. J. Fletterick, "The structure of corepressor Dax-1 bound to its target nuclear receptor LRH-1," Proceedings of the National Academy of Sciences of the United States of America, vol. 105, no. 47, pp. 18390-18395, 2008.

[62] A. K. Iyer, Y.-H. Zhang, and E. R. B. McCabe, "Dosage-sensitive sex reversal adrenal hypoplasia congenita critical region on the $\mathrm{X}$ chromosome, gene 1 (DAX1) (NR0B1) and Small Heterodimer Partner (SHP) (NROB2) form homodimers individually, as well as DAX1-SHP heterodimers," Molecular Endocrinology, vol. 20, no. 10, pp. 2326-2342, 2006.

[63] P. A. Crawford, C. Dorn, Y. Sadovsky, and J. Milbrandt, "Nuclear receptor $D A X-1$ recruits nuclear receptor corepressor N-CoR to steroidogenic factor 1," Molecular and Cellular Biology, vol. 18, no. 5, pp. 2949-2956, 1998.

[64] B. Altincicek, S. P. Tenbaum, U. Drossel, D. Thormeyer, R. Renkawitz, and A. Baniahmad, "Interaction of the corepressor alien with $D A X-1$ is abrogated by mutations of $D A X-1$ involved in adrenal hypoplasia congenita," The Journal of Biological Chemistry, vol. 275, no. 11, pp. 7662-7667, 2000.

[65] S. G. Lehmann, E. Lalli, and P. Sassone-Corsi, "X-linked adrenal hypoplasia congenita is caused by abnormal nuclear localization of the DAX-1 protein," Proceedings of the National Academy of Sciences of the United States of America, vol. 99, no. 12, pp. 82258230, 2002.

[66] S. G. Lehmann, J.-M. Wurtz, J.-P. Renaud, P. Sassone-Corsi, and E. Lalli, "Structure-function analysis reveals the molecular determinants of the impaired biological function of $D A X-1$ mutants in AHC patients," Human Molecular Genetics, vol. 12, no. 9, pp. 1063-1072, 2003.

[67] S. Gray and M. Levine, "Transcriptional repression in development," Current Opinion in Cell Biology, vol. 8, pp. 358-364, 1996.

[68] Y. Qiu, F. A. Pereira, F. J. DeMayo, J. P. Lydon, S. Y. Tsai, and M. J. Tsai, "Null mutation of mCOUP-TFI results in defects in morphogenesis of the glossopharyngeal ganglion, axonal projection, and arborization," Genes \& Development, vol. 11, no. 15, pp. 1925-1937, 1997.

[69] F. A. Pereira, Q. Yuhong, G. Zhou, M.-J. Tsai, and S. Y. Tsai, "The orphan nuclear receptor COUP-TFII is required for angiogenesis and heart development," Genes \& Development, vol. 13, no. 8, pp. 1037-1049, 1999.

[70] E. Lalli, K. Ohe, C. Hindelang, and P. Sassone-Corsi, "Orphan receptor $D A X-1$ is a shuttling RNA binding protein associated with polyribosomes via mRNA," Molecular and Cellular Biology, vol. 20, no. 13, pp. 4910-4921, 2000.

[71] B. Xu, W.-H. Yang, I. Gerin, C.-D. Hu, G. D. Hammer, and R. J. Koenig, "Dax-1 and steroid receptor RNA activator (SRA) function as transcriptional coactivators for steroidogenic factor 1 in steroidogenesis," Molecular and Cellular Biology, vol. 29, no. 7, pp. 1719-1734, 2009.

[72] O. Zwermann, F. Beuschlein, E. Lalli, A. Klink, P. Sassone-Corsi, and M. Reincke, "Clinical and molecular evidence for DAX-1 inhibition of steroidogenic factor-1-dependent ACTH receptor gene expression," European Journal of Endocrinology, vol. 152, no. 5, pp. 769-776, 2005.

[73] B. Ferraz-de-Souza, F. Martin, D. Mallet et al., "CBP/p300interacting transactivator, with Glu/Asp-rich C-terminal domain, 2, and pre-B-cell leukemia transcription factor 1 in human adrenal development and disease," Journal of Clinical Endocrinology and Metabolism, vol. 94, no. 2, pp. 678-683, 2009.

[74] A. A. Verrijn Stuart, G. Ozisik, M. A. de Vroede et al., "Clinical case seminar: an amino-terminal DAX1 (NROB1) missense mutation associated with isolated mineralocorticoid deficiency," Journal of Clinical Endocrinology and Metabolism, vol. 92, no. 3, pp. 755-761, 2007.

[75] V. R. Kelly, B. Xu, R. Kuick, R. J. Koenig, and G. D. Hammer, "Dax1 up-regulates Oct4 expression in mouse embryonic stem cells via LRH-1 and SRA," Molecular Endocrinology, vol. 24, no. 12, pp. 2281-2291, 2010.

[76] J. Kim, D. Prawitt, N. Bardeesy et al., “The Wilms' tumor suppressor gene (wt1) product regulates Dax-1 gene expression during gonadal differentiation," Molecular and Cellular Biology, vol. 19, no. 3, pp. 2289-2299, 1999.

[77] B. Skinningsrud, E. S. Husebye, G. D. Gilfillan et al., "Xlinked congenital adrenal hypoplasia with hypogonadotropic hypogonadism caused by an inversion disrupting a conserved noncoding element upstream of the NROB1 (DAX1) gene," Journal of Clinical Endocrinology and Metabolism, vol. 94, no. 10, pp. 4086-4093, 2009.

[78] M. Barbaro, M. Oscarson, J. Schoumans, J. Staaf, S. A. Ivarsson, and A. Wedell, "Isolated 46,XY gonadal dysgenesis in two sisters caused by a Xp21.2 interstitial duplication containing the DAX1 gene," Journal of Clinical Endocrinology and Metabolism, vol. 92, no. 8, pp. 3305-3313, 2007.

[79] A. El Wakil and E. Lalli, "The Wnt/beta-catenin pathway in adrenocortical development and cancer," Molecular and Cellular Endocrinology, vol. 332, no. 1-2, pp. 32-37, 2011.

[80] S. Vainio, M. Heikkilä, A. Kispert, N. Chin, and A. P. McMahon, "Female development in mammals is regulated by Wnt-4 signalling," Nature, vol. 397, no. 6718, pp. 405-409, 1999.

[81] B. K. Jordan, M. Mohammed, S. T. Ching et al., "Up-regulation of WNT-4 signaling and dosage-sensitive sex reversal in humans," American Journal of Human Genetics, vol. 68, no. 5, pp. 1102-1109, 2001.

[82] H. Mizusaki, K. Kawabe, T. Mukai et al., "Dax-1 (dosagesensitive sex reversal-adrenal hypoplasia congenita critical region on the $\mathrm{X}$ chromosome, gene 1) gene transcription is regulated by wnt 4 in the female developing gonad," Molecular Endocrinology, vol. 17, no. 4, pp. 507-519, 2003.

[83] H. Osman, C. Murigande, A. Nadakal, and A. M. Capponi, "Repression of DAX-1 and induction of SF-1 expression: two mechanisms contributing to the activation of aldosterone biosynthesis in adrenal glomerulosa cells," The Journal of Biological Chemistry, vol. 277, no. 43, pp. 41259-41267, 2002.

[84] T. Yazawa, T. Mizutani, K. Yamada et al., "Involvement of cyclic adenosine $5^{\prime}$-monophosphate response element-binding protein, steroidogenic factor 1 , and Dax-1 in the regulation of gonadotropin-inducible ovarian transcription factor 1 gene expression by follicle-stimulating hormone in ovarian granulosa cells," Endocrinology, vol. 144, no. 5, pp. 1920-1930, 2003.

[85] B. M. Gummow, J. O. Scheys, V. R. Cancelli, and G. D. Hammer, "Reciprocal regulation of a glucocorticoid receptorsteroidogenic factor-1 transcription complex on the Dax-1 promoter by glucocorticoids and adrenocorticotropic hormone 
in the adrenal cortex," Molecular Endocrinology, vol. 20, no. 11, pp. 2711-2723, 2006.

[86] G. B. Kletter, J. L. Gorski, and R. P. Kelch, "Congenital adrenal hypoplasia and isolated gonadotropin deficiency," Trends in Endocrinology and Metabolism, vol. 2, no. 4, pp. 123-128, 1991.

[87] R. L. Habiby, P. Boepple, L. Nachtigall, P. M. Sluss, W. F. Crowley Jr., and J. L. Jameson, "Adrenal hypoplasia congenita with hypogonadotropic hypogonadism. Evidence that $D A X-$ 1 mutations lead to combined hypothalamic and pituitary defects in gonadotropin production," The Journal of Clinical Investigation, vol. 98, no. 4, pp. 1055-1062, 1996.

[88] T. Takahashi, Y. Shoji, Y. Shoji, N. Haraguchi, I. Takahashi, and G. Takada, "Active hypothalamic-pituitary-gonadal axis in an infant with X-linked adrenal hypoplasia congenita," The Journal of Pediatrics, vol. 130, no. 3, pp. 485-488, 1997.

[89] K. B. Kaiserman, J. M. Nakamoto, M. E. Geffner, and E. R. B. McCabe, "Minipuberty of infancy and adolescent pubertal function in adrenal hypoplasia congenita," Journal of Pediatrics, vol. 133, no. 2, pp. 300-302, 1998.

[90] I. Takahashi, T. Takahashi, Y. Shoji, and G. Takada, "Prolonged activation of the hypothalamus-pituitary-gonadal axis in a child with X-linked adrenal hypoplasia congenita," Clinical Endocrinology, vol. 53, no. 1, pp. 127-129, 2000.

[91] D. P. Merke, T. Tajima, J. Baron, and G. B. Cutler Jr., "Hypogonadotropic hypogonadism in a female caused by an X-linked recessive mutation in the DAX1 gene," The New England Journal of Medicine, vol. 340, no. 16, pp. 1248-1252, 1999.

[92] J. C. Achermann, W.-X. Gu, T. J. Kotlar et al., "Mutational analysis of DAX1 in patients with hypogonadotropic hypogonadism or pubertal delay," Journal of Clinical Endocrinology and Metabolism, vol. 84, no. 12, pp. 4497-4500, 1999.

[93] G. Mantovani, G. Ozisik, J. C. Achermann et al., "Hypogonadotropic hypogonadism as a presenting feature of late-onset X-linked adrenal hypoplasia congenita," Journal of Clinical Endocrinology and Metabolism, vol. 87, no. 1, pp. 44-48, 2002.

[94] C. Frapsauce, C. Ravel, M. Legendre et al., "Birth after TESEICSI in a man with hypogonadotropic hypogonadism and congenital adrenal hypoplasia linked to a DAX-1 (NR0B1) mutation," Human Reproduction, vol. 26, no. 3, pp. 724-728, 2011.

[95] K.-Y. Loke, L. K.-S. Poh, W. W.-R. Lee, and P.-S. Lai, "A case of X-linked adrenal hypoplasia congenita, central precocious puberty and absence of the DAX-1 gene: implications for pubertal regulation," Hormone Research, vol. 71, no. 5, pp. 298304, 2009.

[96] S. Darcan, D. Göksen, S. Özen, F. Ozkinay, B. Durmaz, and E. Lalli, "Gonadotropin-dependent precocious puberty in a patient with X-linked adrenal hypoplasia congenita caused by a novel DAX-1 mutation," Hormone Research in Paediatrics, vol. 75, no. 2, pp. 153-156, 2011.

[97] S. Domenice, A. C. Latronico, V. N. Brito, I. J. P. Arnhold, F. Kok, and B. B. Mendonca, "Clinical case seminar: adrenocorticotropin-dependent precocious puberty of testicular origin in a boy with X-linked adrenal hypoplasia congenita due to a novel mutation in the DAX1 gene," Journal of Clinical Endocrinology and Metabolism, vol. 86, no. 9, pp. 4068-4071, 2001.

[98] M. G. Shaikh, L. Boyes, H. Kingston et al., "Skewed X inactivation is associated with phenotype in a female with adrenal hypoplasia congenita," Journal of Medical Genetics, vol. 45, no. 9, p. e1, 2008.
[99] J. K. Phelan and E. R. B. Mccabe, "Mutations in NROB1 (DAX1) and NR5A1 (SF1) responsible for adrenal hypoplasia congenita," Human Mutation, vol. 18, no. 6, pp. 472-487, 2001.

[100] L. Lin, W.-X. Gu, G. Ozisik et al., "Analysis of DAX1 (NR0B1) and steroidogenic factor-1 (NR5Al) in children and adults with primary adrenal failure: ten years' experience," Journal of Clinical Endocrinology and Metabolism, vol. 91, no. 8, pp. 30483054, 2006.

[101] R. El-Khairi, A. Martinez-Aguayo, B. Ferraz-de-Souza, L. Lin, and J. C. Achermann, "Role of DAX-1 (NROB1) and steroidogenic factor-1 (NR5A1) in human adrenal function," Endocrine Development, vol. 20, pp. 38-46, 2010.

[102] P. Bernard, L. Ludbrook, G. Queipo et al., "A familial missense mutation in the hinge region of DAX1 associated with lateonset AHC in a prepubertal female," Molecular Genetics and Metabolism, vol. 88, no. 3, pp. 272-279, 2006.

[103] A. Tabarin, J. C. Achermann, D. Recan et al., "A novel mutation in $D A X 1$ causes delayed-onset adrenal insufficiency and incomplete hypogonadotropic hypogonadism," The Journal of Clinical Investigation, vol. 105, no. 3, pp. 321-328, 2000.

[104] G. Ozisik, G. Mantovani, J. C. Achermann et al., "An alternate translation initiation site circumvents an amino-terminal DAX1 nonsense mutation leading to a mild form of X-linked adrenal hypoplasia congenita," Journal of Clinical Endocrinology and Metabolism, vol. 88, no. 1, pp. 417-423, 2003.

[105] P. Laissue, S. Copelli, I. Bergada et al., "Partial defects in transcriptional activity of two novel $D A X-1$ mutations in childhoodonset adrenal hypoplasia congenita," Clinical Endocrinology, vol. 65, no. 5, pp. 681-686, 2006.

[106] V. Perissi, L. M. Staszewski, E. M. McInerney et al., "Molecular determinants of nuclear receptor-corepressor interaction," Genes \& Development, vol. 13, no. 24, pp. 3198-3208, 1999.

[107] L. Nagy, H.-Y. Kao, J. D. Love et al., "Mechanism of corepressor binding and release from nuclear hormone receptors," Genes \& Development, vol. 13, no. 24, pp. 3209-3216, 1999.

[108] H. E. Xu, T. B. Stanley, V. G. Montana et al., "Structural basis for antagonist-mediated recruitment of nuclear co-repressors by PPAR $\alpha$," Nature, vol. 415, no. 6873, pp. 813-817, 2002.

[109] K. Kawajiri, T. Ikuta, T. Suzuki et al., "Role of the LXXLL-motif and activation function 2 domain in subcellular localization of Dax-1 (dosage-sensitive sex reversal-adrenal hypoplasia congenita critical region on the X chromosome, gene 1)," Molecular Endocrinology, vol. 17, no. 6, pp. 994-1004, 2003.

[110] M.-C. Battista, M. Otis, M. Côté et al., "Extracellular matrix and hormones modulate DAX-1 localization in the human fetal adrenal gland," Journal of Clinical Endocrinology and Metabolism, vol. 90, no. 9, pp. 5426-5431, 2005.

[111] J. O. Scheys, J. H. Heaton, and G. D. Hammer, "Evidence of adrenal failure in aging Daxl-deficient mice," Endocrinology, vol. 152, no. 9, pp. 3430-3439, 2011.

[112] C. Dorn, Q. Ou, J. Svaren, P. A. Crawford, and Y. Sadovsky, "Activation of luteinizing hormone $\beta$ gene by gonadotropinreleasing hormone requires the synergy of early growth response-1 and steroidogenic factor-1," The Journal of Biological Chemistry, vol. 274, no. 20, pp. 13870-13876, 1999.

[113] X. Wei, M. Sasaki, H. Huang, V. L. Dawson, and T. M. Dawson, "The orphan nuclear receptor, steroidogenic factor 1, regulates neuronal nitric oxide synthase gene expression in pituitary gonadotropes," Molecular Endocrinology, vol. 16, no. 12, pp. 2828-2839, 2002.

[114] S. G. Lehmann, P. Sassone-Corsi, and E. Lalli, "Heat shock affects trafficking of $D A X-1$ by inducing its rapid and reversible 
cytoplasmic localization," Endocrine, vol. 28, no. 2, pp. 137-144, 2005.

[115] F. Muscatelli, A. P. Walker, E. de Plaen, A. N. Stafford, and A. P. Monaco, "Isolation and characterization of a MAGE gene family in the Xp21.3 region," Proceedings of the National Academy of Sciences of the United States of America, vol. 92, no. 11, pp. 49874991, 1995.

[116] B. Dabovic, E. Zanaria, B. Bardoni et al., "A family of rapidly evolving genes from the sex reversal critical region in Xp21," Mammalian Genome, vol. 6, no. 9, pp. 571-580, 1995.

[117] A. Swain, V. Narvaez, P. Burgoyne, G. Camerino, and R. Lovell-Badge, "Dax1 antagonizes Sry action in mammalian sex determination," Nature, vol. 391, no. 6669, pp. 761-767, 1998.

[118] P. N. Goodfellow and G. Camerino, "DAX-1, an "antitestis" gene," Cellular and Molecular Life Sciences, vol. 55, no. 6-7, pp. 857-863, 1999.

[119] R. N. Yu, M. Ito, T. L. Saunders, S. A. Camper, and J. L. Jameson, "Role of Ahch in gonadal development and gametogenesis," Nature Genetics, vol. 20, no. 4, pp. 353-357, 1998.

[120] J. J. Meeks, S. E. Crawford, T. A. Russell, K.-I. Morohashi, J. Weiss, and J. L. Jameson, "Daxl regulates testis cord organization during gonadal differentiation," Development, vol. 130, no. 5, pp. 1029-1036, 2003.

[121] B. Jeffs, M. Ito, R. N. Yu et al., "Sertoli cell-specific rescue of fertility, but not testicular pathology, in Daxl (Ahch)-deficient male mice," Endocrinology, vol. 142, no. 6, pp. 2481-2488, 2001.

[122] J. J. Meeks, T. A. Russell, B. Jeffs, I. Huhtaniemi, J. Weiss, and J. L. Jameson, "Leydig cell-specific expression of DAX1 improves fertility of the Dax1-deficient mouse," Biology of Reproduction, vol. 69, no. 1, pp. 154-160, 2003.

[123] B. Jeffs, J. J. Meeks, M. Ito et al., "Blockage of the rete testis and efferent ductules by ectopic sertoli and leydig cells causes infertility in Dax1-deficient male mice," Endocrinology, vol. 142, no. 10, pp. 4486-4495, 2001.

[124] Z. J. Wang, B. Jeffs, M. Ito et al., "Aromatase (Cyp19) expression is up-regulated by targeted disruption of Daxl," Proceedings of the National Academy of Sciences of the United States of America, vol. 98, no. 14, pp. 7988-7993, 2001.

[125] J. J. Meeks, J. Weiss, and J. L. Jameson, "Daxl is required for testis determination," Nature Genetics, vol. 34, no. 1, pp. 32-33, 2003.

[126] G. J. Bouma, K. H. Albrecht, L. L. Washburn, A. K. Recknagel, G. A. Churchill, and E. M. Eicher, "Gonadal sex reversal in mutant Dax1 XY mice: a failure to upregulate Sox9 in pre-Sertoli cells," Development, vol. 132, no. 13, pp. 3045-3054, 2005.

[127] S. Y. Park, J. J. Meeks, G. Raverot et al., "Nuclear receptors Sfl and Daxl function cooperatively to mediate somatic cell differentiation during testis development," Development, vol. 132, no. 10, pp. 2415-2423, 2005.

[128] S. B. Seminara, J. C. Achermann, M. Genel, J. L. Jameson, and W. F. Crowley Jr., "X-linked adrenal hypoplasia congenita: a mutation in DAX1 expands the phenotypic spectrum in males and females," Journal of Clinical Endocrinology and Metabolism, vol. 84, no. 12, pp. 4501-4509, 1999.

[129] L. M. Ludbrook, P. Bernard, S. Bagheri-Fam et al., "Excess DAX1 leads to XY ovotesticular disorder of sex development (DSD) in mice by inhibiting steroidogenic factor-1 (SF1) activation of the testis enhancer of SRY-box-9 (Sox9)," Endocrinology, vol. 153, no. 4, pp. 1948-1958, 2012.

[130] I. Chambers and A. Smith, "Self-renewal of teratocarcinoma and embryonic stem cells," Oncogene, vol. 23, no. 43, pp. 71507160, 2004.
[131] S. Yamanaka, "Strategies and new developments in the generation of patient-specific pluripotent stem cells," Cell Stem Cell, vol. 1, no. 1, pp. 39-49, 2007.

[132] K. Mitsui, Y. Tokuzawa, H. Itoh et al., “The homeoprotein nanog is required for maintenance of pluripotency in mouse epiblast and ES cells," Cell, vol. 113, no. 5, pp. 631-642, 2003.

[133] K. K. Niakan, E. C. Davis, R. C. Clipsham et al., "Novel role for the orphan nuclear receptor Daxl in embryogenesis, different from steroidogenesis," Molecular Genetics and Metabolism, vol. 88, no. 3, pp. 261-271, 2006.

[134] Y.-H. Loh, Q. Wu, J.-L. Chew et al., "The Oct4 and Nanog transcription network regulates pluripotency in mouse embryonic stem cells," Nature Genetics, vol. 38, no. 4, pp. 431-440, 2006.

[135] J. Wang, S. Rao, J. Chu et al., "A protein interaction network for pluripotency of embryonic stem cells," Nature, vol. 444, no. 7117, pp. 364-368, 2006.

[136] J. Kim, J. Chu, X. Shen, J. Wang, and S. H. Orkin, "An extended transcriptional network for pluripotency of embryonic stem cells," Cell, vol. 132, no. 6, pp. 1049-1061, 2008.

[137] C. Sun, Y. Nakatake, H. Ura et al., "Stem cell-specific expression of Dax 1 is conferred by STAT3 and Oct $3 / 4$ in embryonic stem cells," Biochemical and Biophysical Research Communications, vol. 372, no. 1, pp. 91-96, 2008.

[138] D. L. C. van den Berg, T. Snoek, N. P. Mullin et al., "An Oct4centered protein interaction network in embryonic stem cells," Cell Stem Cell, vol. 6, no. 4, pp. 369-381, 2010.

[139] H. Niwa, J.-I. Miyazaki, and A. G. Smith, "Quantitative expression of Oct-3/4 defines differentiation, dedifferentiation or selfrenewal of ES cells," Nature Genetics, vol. 24, no. 4, pp. 372-376, 2000.

[140] O. Khalfallah, M. Rouleau, P. Barbry, B. Bardoni, and E. Lalli, "Dax-1 knockdown in mouse embryonic stem cells induces loss of pluripotency and multilineage differentiation," Stem Cells, vol. 27, no. 7, pp. 1529-1537, 2009.

[141] E. Lalli and J. Alonso, "Targeting DAX-1 in embryonic stem cells and cancer," Expert Opinion on Therapeutic Targets, vol. 14, no. 2, pp. 169-177, 2010.

[142] J.-C. D. Heng, B. Feng, J. Han et al., “The nuclear receptor Nr5a2 can replace Oct4 in the reprogramming of murine somatic cells to pluripotent cells," Cell Stem Cell, vol. 6, no. 2, pp. 167-174, 2010.

[143] C.-Q. Xie, Y. Jeong, M. Fu et al., "Expression profiling of nuclear receptors in human and mouse embryonic stem cells," Molecular Endocrinology, vol. 23, no. 5, pp. 724-733, 2009.

[144] M. Reincke, F. Beuschlein, E. Lalli et al., "DAX-1 expression in human adrenocortical neoplasms: implications for steroidogenesis," Journal of Clinical Endocrinology and Metabolism, vol. 83, no. 7, pp. 2597-2600, 1998.

[145] H. Shibata, Y. Ikeda, T. Mukai et al., "Expression profiles of COUP-TF, DAX-1, and SF-1 in the human adrenal gland and adrenocortical tumors: possible implications in steroidogenesis," Molecular Genetics and Metabolism, vol. 74, no. 1-2, pp. 206216, 2001.

[146] L. A. Helguero, M. Hedengran Faulds, C. Förster, J.-Å. Gustafsson, and L.-A. Haldosén, " $D A X-1$ expression is regulated during mammary epithelial cell differentiation," Endocrinology, vol. 147, no. 7, pp. 3249-3259, 2006.

[147] E. Lalli, "Methodological pitfalls in the study of $D A X-1$ function," Cell Death and Disease, vol. 5, article e977, 2014.

[148] S. Ikuyama, Y.-M. Mu, K. Ohe et al., "Expression of an orphan nuclear receptor $D A X-1$ in human pituitary adenomas," Clinical Endocrinology, vol. 48, no. 5, pp. 647-654, 1998. 
[149] S. J. B. Aylwin, J. P. Welch, C. L. Davey et al., “The relationship between steroidogenic factor 1 and $D A X-1$ expression and in vitro gonadotropin secretion in human pituitary adenomas," Journal of Clinical Endocrinology and Metabolism, vol. 86, no. 6, pp. 2476-2483, 2001.

[150] M. Abd-Elaziz, J.-I. Akahira, T. Moriya, T. Suzuki, N. Yaegashi, and H. Sasano, "Nuclear receptor DAX-1 in human common epithelial ovarian carcinoma: an independent prognostic factor of clinical outcome," Cancer Science, vol. 94, no. 11, pp. 980-985, 2003.

[151] I. Conde, J. M. Alfaro, B. Fraile, A. Ruíz, R. Paniagua, and M. I. Arenas, " $D A X-1$ expression in human breast cancer: comparison with estrogen receptors ER-alpha, ER-beta and androgen receptor status," Breast Cancer Research, vol. 6, no. 3, pp. R140R148, 2004.

[152] S. Saito, K. Ito, T. Suzuki et al., "Orphan nuclear receptor DAX-1 in human endometrium and its disorders," Cancer Science, vol. 96, no. 10, pp. 645-652, 2005.

[153] Y. Nakamura, T. Suzuki, Y. Arai, and H. Sasano, "Nuclear receptor $D A X 1$ in human prostate cancer: a novel independent biological modulator," Endocrine Journal, vol. 56, no. 1, pp. 3944, 2009.

[154] D.-C. Seo, J.-M. Sung, H.-J. Cho et al., "Gene expression profiling of cancer stem cell in human lung adenocarcinoma A549 cells," Molecular Cancer, vol. 6, article 75, 2007.

[155] T. Oda, T. Tian, M. Inoue et al., "Tumorigenic role of orphan nuclear receptor NROB1 in lung adenocarcinoma," American Journal of Pathology, vol. 175, no. 3, pp. 1235-1245, 2009.

[156] A. Arvand and C. T. Denny, "Biology of EWS/ETS fusions in Ewing's family tumors," Oncogene, vol. 20, no. 40, pp. 5747-5754, 2001.

[157] M. Mendiola, J. Carrillo, E. García et al., "The orphan nuclear receptor $D A X 1$ is up-regulated by the EWS/FLI1 oncoprotein and is highly expressed in Ewing tumors," International Journal of Cancer, vol. 118, no. 6, pp. 1381-1389, 2006.

[158] M. Kinsey, R. Smith, and S. L. Lessnick, "NROB1 is required for the oncogenic phenotype mediated by EWS/FLI in Ewing's sarcoma," Molecular Cancer Research, vol. 4, no. 11, pp. 851-859, 2006.

[159] M. Wachtel, M. Dettling, E. Koscielniak et al., "Gene expression signatures identify rhabdomyosarcoma subtypes and detect a novel $\mathrm{t}(2 ; 2)(\mathrm{q} 35 ; \mathrm{p} 23)$ translocation fusing PAX3 to NCOA1," Cancer Research, vol. 64, no. 16, pp. 5539-5545, 2004.

[160] E. García-Aragoncillo, J. Carrillo, E. Lalli et al., "DAX1, a direct target of EWS/FLI1 oncoprotein, is a principal regulator of cellcycle progression in Ewing's tumor cells," Oncogene, vol. 27, no. 46, pp. 6034-6043, 2008.

[161] K. Gangwal, S. Sankar, P. C. Hollenhorst et al., "Microsatellites as EWS/FLI response elements in Ewing's sarcoma," Proceedings of the National Academy of Sciences of the United States of America, vol. 105, no. 29, pp. 10149-10154, 2008. 

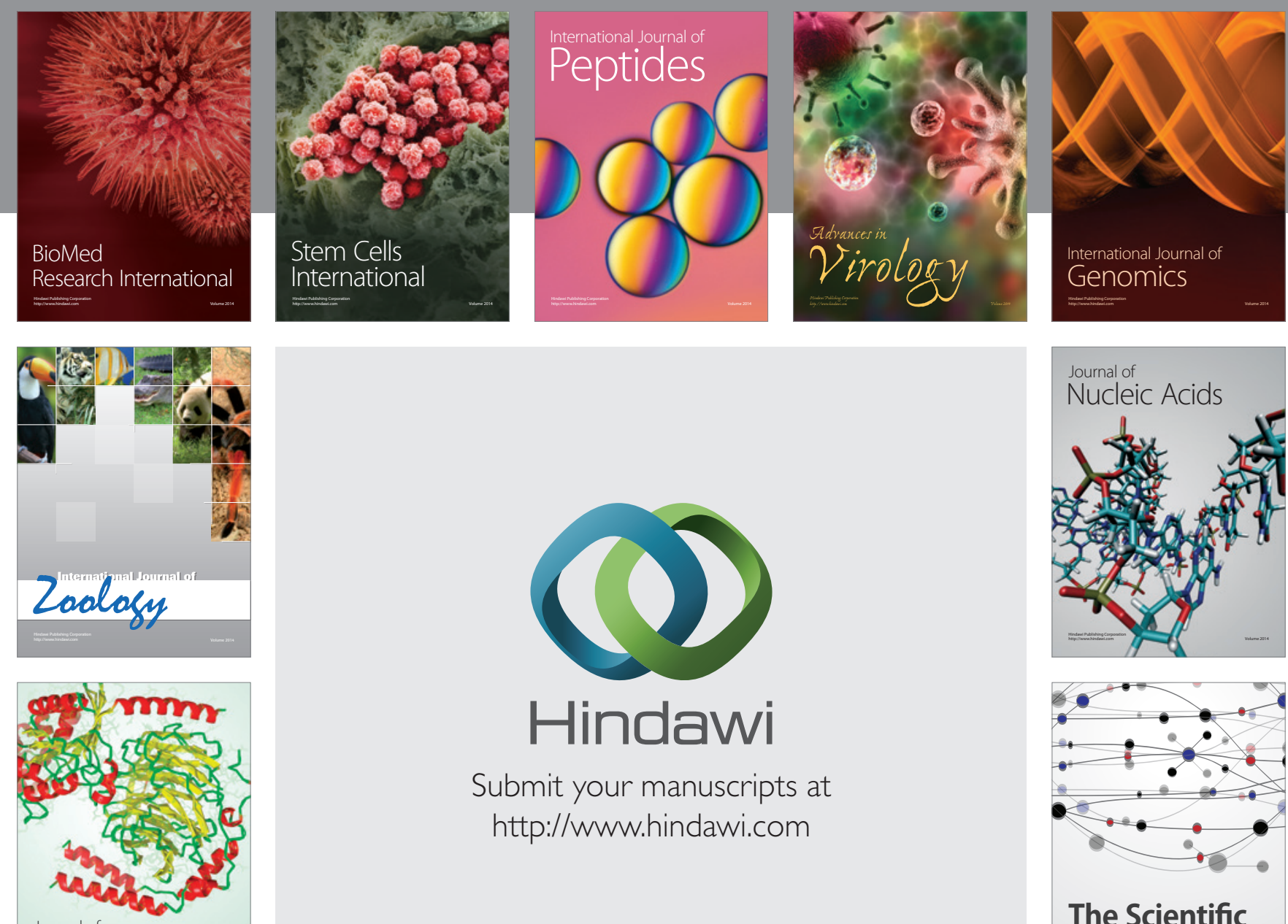

Submit your manuscripts at

http://www.hindawi.com

Journal of
Signal Transduction
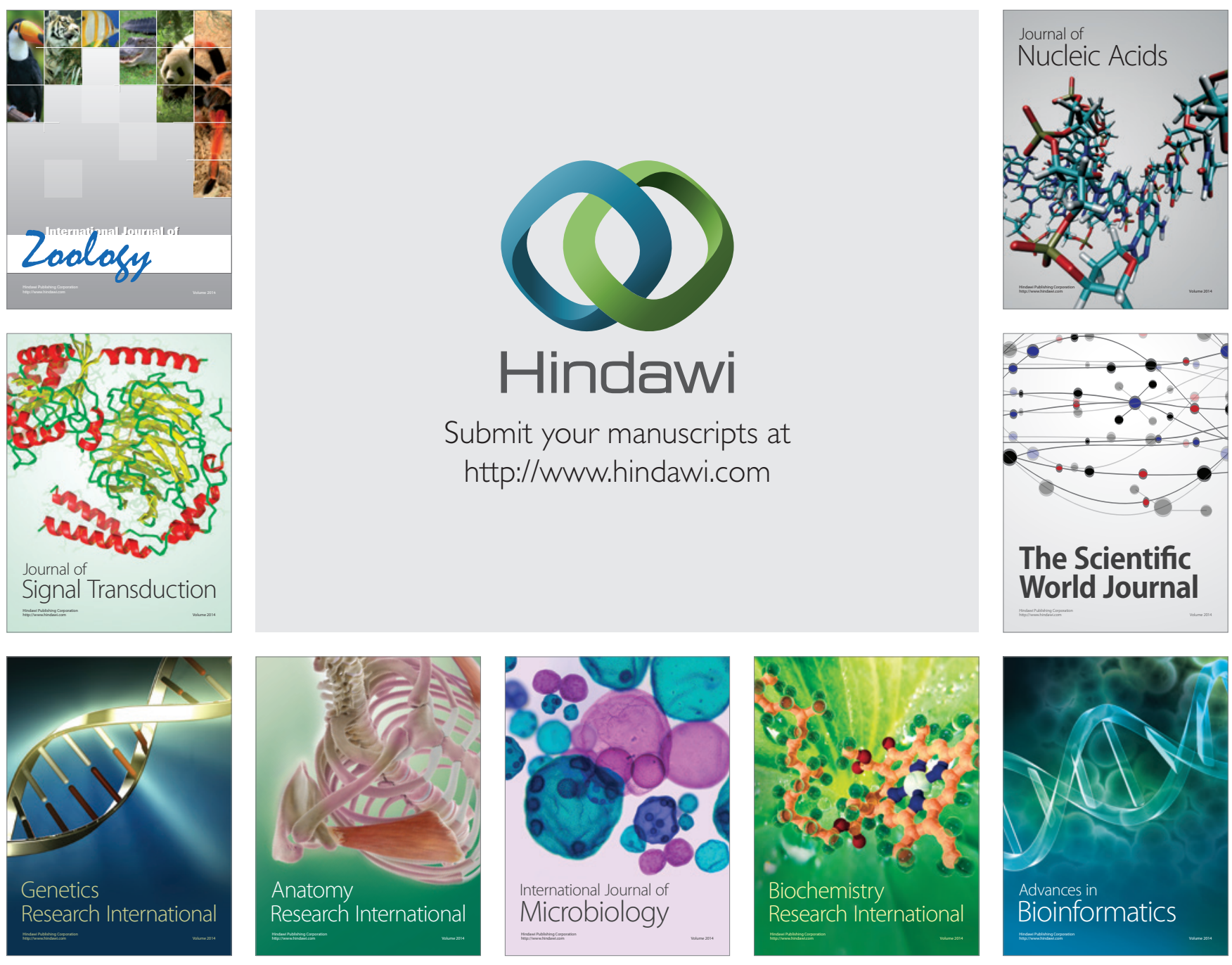

The Scientific World Journal
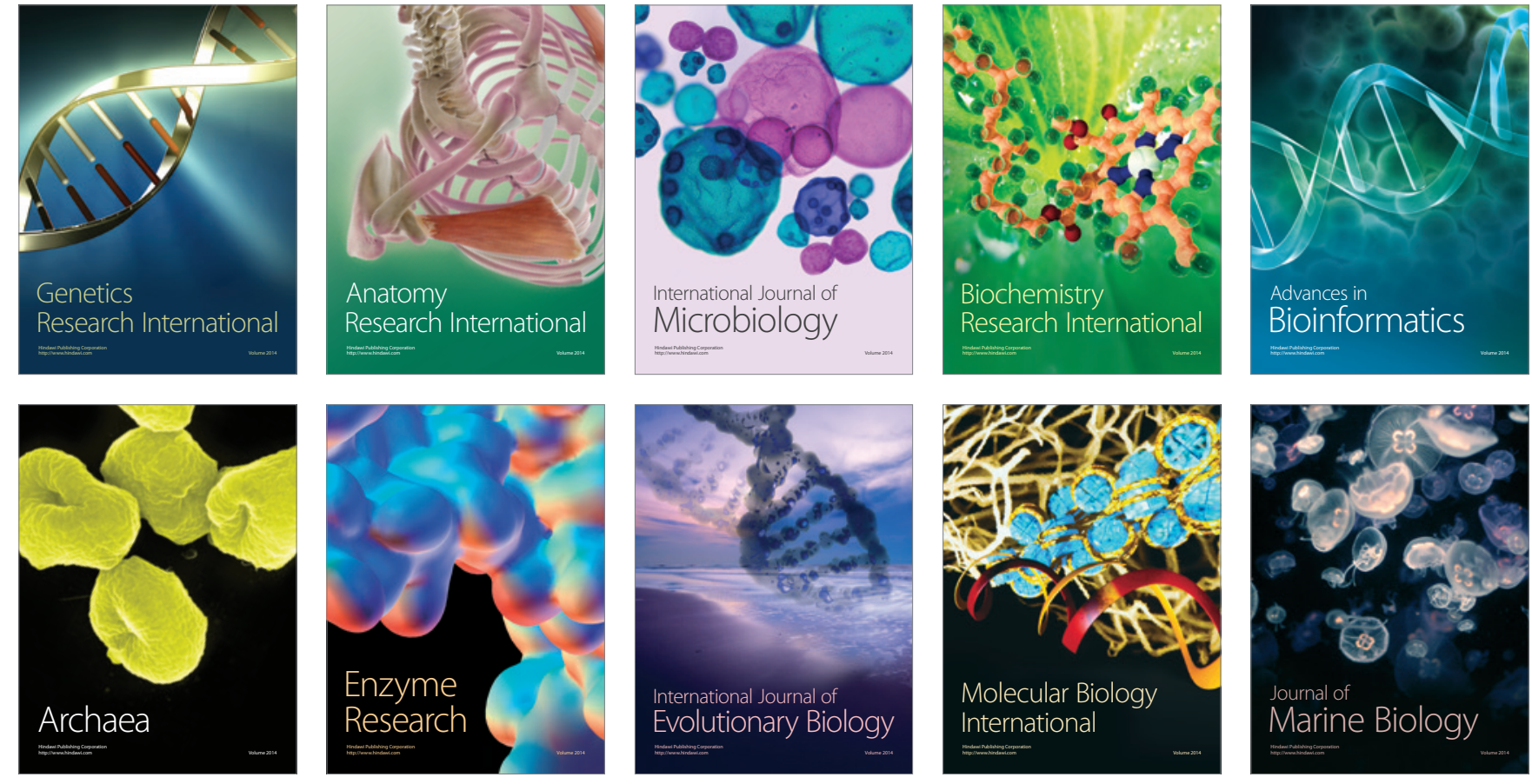